TI 2017-119/VIII

Tinbergen Institute Discussion Paper
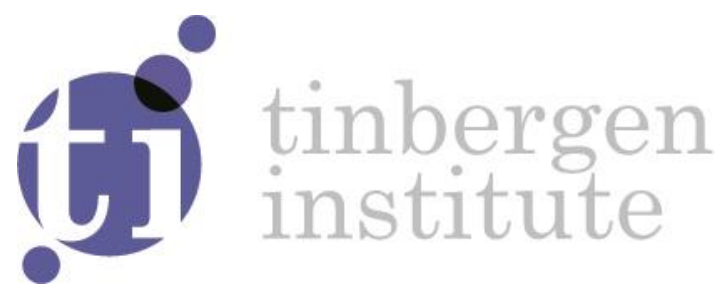

\title{
Crowdfunding public goods: An experiment
}

\section{Erik Ansink ${ }^{1}$}

Mark Koetse ${ }^{3}$

Jetske Bouma2,3

Dominic Hauck ${ }^{3}$

Daan van Soest 4

${ }^{1}$ VU Amsterdam; Tinbergen Institute, The Netherlands

2 Netherlands Environmental Assessment Agency (PBL)

${ }^{3}$ Institute for Environmental Studies, Vrije Universiteit Amsterdam

${ }^{4}$ Department of Economics and CentER, Tilburg University 
Tinbergen Institute is the graduate school and research institute in economics of Erasmus University Rotterdam, the University of Amsterdam and VU University Amsterdam.

Contact: discussionpapers@tinbergen.nl

More TI discussion papers can be downloaded at http://www.tinbergen.nl

Tinbergen Institute has two locations:

Tinbergen Institute Amsterdam

Gustav Mahlerplein 117

1082 MS Amsterdam

The Netherlands

Tel.: +31(0)205984580

Tinbergen Institute Rotterdam

Burg. Oudlaan 50

3062 PA Rotterdam

The Netherlands

Tel.: +31(0)10408 8900 


\title{
Crowdfunding public goods: An experiment*
}

\author{
Erik Ansink, Mark Koetse, ${ }^{b}$ Jetske Bouma, \\ Dominic Hauck, Daan van Soest ${ }^{b}$
}

December 14, 2017

\begin{abstract}
We assess the impact of different crowdfunding designs on the success of crowdfunded public goods using a lab-in-the-field experiment. Our design treatments aim to increase the efficiency of crowdfunding campaigns by raising aggregate contributions and decreasing possible coordination problems that may occur when potential donors are faced with a multitude of projects seeking contributions. Amongst others, we explore the potential of seed money and the impact of the attraction effect. Using a four-day time window we implement our crowdfunding experiment using a web-based user interface with multiple threshold public goods, similar in style to conventional crowdfunding websites. We find that such alternative crowdfunding designs affect efficiency via improving coordination, and not so much via affecting total contributions. These results are confirmed in a follow-up framed field experiment with actual nature conservation projects.
\end{abstract}

JEL Classification: C93, H41, L31, Q57

Keywords: Crowdfunding, lab-in-the-field experiment, threshold public goods, charitable giving, nature conservation

*We thank Harold Houba, Jos van Ommeren, seminar participants at Vrije Universiteit Amsterdam, EAERE 2017, BioEcon 2017, Netherlands Economists Day 2017, and the 2017 Workshop on Experimental Economics for the Environment in Bremen for comments, suggestions, and discussion. We thank Natuurmonumenten and Kantar TNS for excellent support and advice. We are grateful to the Netherlands Environmental Assessment Agency for financial support. Ansink, Bouma, and Hauck gratefully acknowledge financial support from the Netherlands Organisation for Scientific Research (NWO) Grant No. 841.12.002. Koetse gratefully acknowledges funding from the European Commission $7^{\text {th }}$ Framework Programme Grant No. 308393. Van Soest gratefully acknowledges funding from the European Commission $7^{\text {th }}$ Framework Program Grant No. 613420.

${ }^{a}$ Department of Spatial Economics, Vrije Universiteit Amsterdam, and Tinbergen Institute.

${ }^{b}$ Institute for Environmental Studies, Vrije Universiteit Amsterdam.

${ }^{c}$ Netherlands Environmental Assessment Agency (PBL) and Institute for Environmental Studies, Vrije Universiteit Amsterdam.

${ }^{d}$ Department of Economics and CentER, Tilburg University. 


\section{Introduction}

Crowdfunding websites are increasingly being used as a mechanism for the provision of public goods. Crowdfunding is the practice of a fund-raiser raising capital from many investors to fund a project through an on-line platform. Crowdfunding is new, with wellknown platforms such as FundRazr, GoFundMe, Kickstarter, and IndieGoGo having been launched only in the late 2000s. The crowdfunding of public goods, sometimes referred to by the more encompassing term 'civic' crowdfunding (Davies, 2015; Stiver et al., 2015; Chovanculiak and Hudik, 2017), has found its niche on these platforms but its popularity also initiated specialized crowdfunding websites such as Citizinvestor, IOBY, JustGiving, and GlobalGiving. A large share of civic crowdfunding involves projects related to urban commons (e.g. gardens, parks, events), education, infrastructure, and environment/wildlife (Charbit and Desmoulins, 2017).

Using crowdfunding as a mechanism to provide public goods may mitigate several obstacles that are normally associated with private public good provisioning. For instance, compared to alternative mechanisms, crowdfunding allows cheap matching between projects and potential donors through low search costs, low risk exposure, low demand uncertainty, and transparent monitoring of progress (Cornes and Sandler, 1996; Agrawal et al., 2014; Strausz, 2017). Yet, other obstacles remain, including cheap-riding and coordination problems. Cheap-riding occurs whenever agents contribute to the public good but try to reach an outcome where their own relative contribution is low (Isaac et al., 1989). Coordination failure occurs when the multiplicity of projects offered on a crowdfunding platform causes an 'inefficient distribution of donations across projects' (Corazzini et al., 2015, p17), possibly leading to project failure and discouraging potential donors. As sometimes half of the projects fail (see for example Mollick, 2014, for the case of Kickstarter), there is room for improvement - raising the total contributions to public goods projects, or improving coordination on specific projects.

Most crowdfunding platforms offer an all-or-nothing design, where contributions are effectuated only if a pre-specified threshold is met. This design thus mimics a threshold public goods game with full refund - a design which is known to boost donations in such games (Cadsby and Maynes, 1999). Yet, by itself this design does not solve cheap-riding and coordination problems, which potentially have more impact on crowdfunding success. Both cheap-riding and coordination problems could be further mitigated by signaling focal projects, for instance by promoting such projects more prominently on the crowdfunding platform. Signaling has been demonstrated to facilitate success in coordination games (Schelling, 1960; Mehta et al., 1994). In crowdfunding, signals used by fund-raisers include 
short time windows and high thresholds while signals used by the platforms include all kinds of website design options such as the selection of featured projects (Mollick, 2014; Belleflamme et al., 2015; Devaraj and Patel, 2016) 11 Identification of the impact of such signals in practice is inevitably muddled by endogeneity problems.

In this paper we rigorously test the impact of various crowdfunding designs, and specifically the use of focal projects, on project success. We do so using a lab-in-the-field experiment to control for possible endogeneity problems. We investigate two mechanisms that aim to raise total contributions and/or facilitate coordination by signaling focal projects. The first is the provision of seed money (also known as 'challenge gifts': List and LuckingReiley, 2002; Rondeau and List, 2008). The second mechanism is adding a seemingly irrelevant project that serves as a decoy in order to exploit the so-called attraction effect (cf. Ariely and Wallsten, 1995). From the crowdfunding platform and fund-raisers' perspective, our contribution is that we analyze whether the number of successful projects can be increased through the mitigation of cheap-riding and coordination failure, and if so, how: ${ }^{2}$

Our lab-in-the-field experiment aims to extend the insights obtained by earlier crowdfunding experiments in the laboratory in two respects (Wash and Solomon, 2014; Corazzini et al., 2015; Solomon et al., 2015). First, our lab-in-the-field experiment took place over a period of four days (Thursday mornings to Sunday evenings), with subjects being able to $\log$ in to the internet-based user interface of the game using any device at any moment from any location, to make contribution decisions for one or more projects. This set-up is very different from the typical lab experiment on crowdfunding, where a session lasts for about one hour, and where multiple rounds are being played in an environment without distractions. This lab setting may cause subjects to be more sensitive to (subtle) differences in project characteristics than they would otherwise be when making their decisions in case of an actual crowdfunding event. Second, running a lab-in-the-field experiment allowed us to use a representative sample of the relevant population as opposed to WEIRD students. ${ }^{3}$ A follow-up framed field experiment with actual nature conservation projects, described in Section 5 , brings us even closer to the field.

Some of our results, reported in Section 4, confirm earlier findings, such as coordination

\footnotetext{
${ }^{1}$ Other aspects that affect crowdfunding success but are not under control of the fund-raiser include the number of potential donors, social norms, the characteristics of early funders, and herding (cf. Bøg et al. 2012; Crosetto and Regner, 2014; Belleflamme et al., 2015). Note that there exist modest differences in donor behavior between for-profit and non-profit crowdfunding campaigns (Pitschner and Pitschner-Finn, 2014).

${ }^{2}$ Our methodology does not allow us, however, to assess the impact of our crowdfunding designs on substitution to and away from contributions to other projects, charities, and investments on other crowdfunding platforms or using alternative fund-raising mechanisms.

${ }^{3}$ White, Educated, Industrialized, Rich, and Democratic; see Henrich et al. (2010).
} 
difficulties in general. Our analysis of the impact of seeding and seemingly irrelevant alternatives yields new findings. Our results reveal that such mechanisms affect coordination, and not so much the total amount contributed. Consistent with our expectations, seeded projects serve as focal projects, receiving relatively more contributions and displaying a higher success rate. This effect, however, only occurs when the number of available projects is high (6) and not when it is low (2). Perhaps counter-intuitively, adding a seemingly irrelevant project does not lead to an attraction effect, but rather a repulsion effect, with the decoy project diverting contributions from its target project rather than increasing them.

In general, our results demonstrate that signals do work in the context of crowdfunding and that they can be exploited in order to mitigate coordination failure and cheap-riding. These results confirm the coordination results found by Corazzini et al. (2015) in a lab setting and provide further support for crowdfunding as a promising mechanism for the private provision of public goods. $4^{4}$ As such, our results are of interest to platforms, fundraisers, and funders of civic crowdfunding projects.

\section{Experimental design}

The game that we implement is an on-line real-time linear threshold public goods game without rebate (if contributions exceed the threshold) but with full refund (if the threshold fails to be met). The linear version of the public goods game is also known as the voluntary contribution mechanism and has been widely used to study efficiency and behavioral aspects of various mechanisms and design options in the provisioning of public goods. To mimic the crowdfunding setting we choose six specific game features. First, subjects do not come to a lab but play the game on-line using a web-based user interface, similar in style to conventional crowdfunding websites. Second, the game is played in real-time over the course of four days, allowing subjects to incrementally raise their contributions to the public good, up to the end of the campaign's time window (Dorsey, 1992; Kurzban et al. 2001; Goren et al., 2003; Duffy et al., 2007). The time-span of four days was selected as a compromise between the length of conventional crowdfunding campaigns on the one side and keeping subjects' attention and limiting their time investment on the other side. Third, we present multiple public goods projects at once, offering subjects the choice to invest in more than one project, if any (Corazzini et al., 2015). Fourth, we impose an exogenous threshold value that serves as the minimum level of aggregate contributions required to

\footnotetext{
${ }^{4}$ Note that civic crowdfunding could either substitute or complement government-provided public goods (Davies, 2015).
} 
implement the public good which provides a discrete payoff bonus to each subject in the group (van de Kragt et al., 1983; Palfrey and Rosenthal, 1984; Bagnoli and Lipman, 1989). Fifth, there is no rebate of excess contributions (Marks and Croson, 1998; Spencer et al., 2009). Sixth, in line with common practice at major crowdfunding platforms we implement full refund, i.e. a money-back guarantee in case the threshold is not reached (Isaac et al., 1989; Wash and Solomon, 2014).

Our analysis is based on a between-subject design across five treatments. In our benchmark treatment, subjects have the option to contribute to two threshold public goods that differ in the threshold contribution that needs to be made for the project to go through, and in the bonus each subject receives if indeed the threshold is met. Both projects are presented simultaneously in a user interface further described below (and see Appendix A). Subsequent treatments differ from the benchmark treatment in terms of the number of goods and their characteristics. All treatments were played by 90 subjects, distributed over 15 groups of 6 subjects each. In total, across treatments, 450 subjects participated in the experiment.

\subsection{Benchmark treatment}

In the benchmark treatment, that we refer to as BEN, subjects were randomly assigned to groups of six. Upon logging in to the user interface, each subject received a one-time endowment of 34 tokens (worth EUR 0.20 per token) in his private account. Subjects could use this endowment over the course of the game, which lasted from Thursday 8 a.m. to Sunday 10 p.m., to contribute to one or both of two threshold public goods by investing (but not divesting), part or all of their endowment, either at once, or in smaller steps. The public goods are collective accounts, where each subject within a group can contribute to. When the threshold for a public good is reached at the game deadline (i.e. Sunday 10 p.m.), contributions to that good are effectuated (i.e. deducted from the private accounts) and a bonus is paid to each subject in the group regardless of their individual contributions to the public good. When the threshold for a public good fails to be reached at the game deadline, the bonus is not paid out and any contributions to that public good project are returned to the contributors' private accounts. Subjects' payoffs are the sum of what is left in their private accounts plus any bonus received from one or both goods.

The two goods differ in threshold and bonus and we refer to them as Good $72_{18}$ and Good $84_{24}$. Good $72_{18}$ has a threshold value of 72 and pays a bonus of 18 to each of the six subjects in the group, while good $84_{24}$ has a threshold value of 84 and a per-subject bonus of 24 . Hence, good $72_{18}$ is easier to implement since it has a lower threshold (72 vs. 
84) while $84_{24}$ offers a higher net payoff to the group as a whole (108 vs. 144). Group payoffs are maximized if both thresholds are met, but note that this requires (substantial) contributions of at least five players; the initial endowments are such that four or fewer subjects cannot finance both goods $(4 \times 34<72+84)$.

\subsection{Other treatments}

To test the impact of various crowdfunding design choices, we implement four variations on the benchmark treatment, that differ from BEN in terms of the number of goods and their characteristics. Motivation for treatment characteristics and a discussion of expected behavior under these treatments is deferred to Section 3 , while an overview of treatments is provided in Table 1 .

Table 1: Overview of projects in all treatments.

\begin{tabular}{ll}
\hline Treatment & Project characteristics \\
\hline BEN & $72_{18}, 84_{24}$ \\
SEED72* & $92_{18}, 84_{24}$ \\
SIA72 & $72_{18}, 84_{24}, 72_{17}$ \\
SIX & $72_{18}, 84_{24}, 74_{16}, 78_{17}, 86_{22}, 90_{23}$ \\
SIXSEED78** & $72_{18}, 84_{24}, 74_{16}, 98_{17}, 86_{22}, 90_{23}$ \\
\hline
\end{tabular}

* Underlined good differs from its related good under BEN by an anonymous initial contribution of 20 tokens as well as an increase in its threshold of 20 tokens, making the two goods formally equivalent.

** Idem, but related to SIX rather than BEN.

In two treatments, SEED72 and SIA72, we focus attention on the least successful good in BEN. In Section 4 we show that $72_{18}$ is less successful than $84_{24}$, both in terms of total contributions and in terms of thresholds' reached. We focus attention on this good in two distinct ways. In SEED72 we add 20 seed tokens to $72_{18}$ at the start of the game and raise its threshold by an equal amount of tokens to create $92_{18}$. Because the bonus paid in case of success remains unchanged, $92_{18}$ under SEED72 is formally equivalent to $72_{18}$ under BEN, although subjects may perceive this differently. In SIA72 we add a third 'seemingly irrelevant alternative' good to the two BEN goods, $72_{17}$, serving as a decoy to $72_{18}$. For the same threshold contribution its bonus is lower, and hence $72_{17}$ is dominated by $72_{18}$.

In the next two treatments, SIX and SIXSEED78, we increase the number of available goods from two to six. Coordination failures are more likely to arise when more projects are available. In SIX, we add four goods that are dominated by the two BEN goods in terms of both their thresholds and bonuses. These four goods' characteristics are, respectively, 
$74_{16}, 78_{17}, 86_{22}$, and $90_{23}$, so that each good under SIX has a distinct threshold and bonus. In SIXSEED78, similar to SEED72, we add 20 seed tokens to the least successful good under SIX and raise its threshold by an equal amount of tokens. In Section 4 we show that this least successful good is $78_{17}$, and hence we create $98_{17}$ to be implemented in SIXSEED78. A variation of treatment SIX with an additional seemingly irrelevant project ('SIXSIA78') would not make much sense, given that four of the six projects in this treatment are already dominated and relatively similar to one of the two BEN goods.

\subsection{Sampling and procedures}

Subjects were sampled from a survey panel hosted by Kantar TNS, a Dutch survey consultancy. All communication with subjects was done via email by the consultancy. Subjects were invited to participate about one month in advance, asking them for their availability to participate in an on-line game and log in at least once a day over the course of four specified days. From the sample, sub-samples for each treatment were formed that were representative for the Dutch population in terms of gender, age, and education. Three days prior to the experiment, subjects were reminded of the experiment and given the opportunity to cancel their participation. One day before the start of the experiment, an email was sent to all participating subjects with game instructions and a personal login URL. These game instructions were accessible from the user interface throughout the experiment. The experiment took place in three sessions (first BEN, then SIA72 and SIX, and finally SEED72 and SIXSEED78), each lasting from Thursday 8 a.m. to Sunday 10 p.m., and were conducted in the period of October-November 2015. Each day of the four-day session a reminder email was sent before noon to each subject with their personal login URL, irrespective of whether they had already logged in on that day.

Any subjects who canceled their participation prior to the start of the experiment were replaced by subjects from a standby sample. In order to assure full groups of active contributors we also allowed replacement on the first day of the game. We intended to replace any subject who did not login on Thursday before 10 p.m. by a subject from the same standby sample. As the discussion on group size in Section 4 shows, we were able to replace only a share of those subjects, which caused us to exclude a number of groups from the analysis. Other subjects in the group were not informed of such replacements, nor could they derive this information through the user interface.

Instructions (see Appendix E) included the game objective, the rules of play, calculation of payoffs, an extensive example, and a FAQ list which was compiled based on the evaluation of a pilot study of the benchmark treatment in October 2015. Instructions were kept as brief 
as possible since they had to be read on-screen. The specific wording was based on multiple rounds of testing and evaluation during the pilot study. Based on this evaluation, we framed the public goods as 'projects' and contributions as 'investments', without expecting significant impact of this framing on game behavior (Alekseev et al., 2017); 5 we will use the terms interchangeably throughout the paper. Contact information to a designated contact person at the research consultancy was provided in case anything was unclear (20 of our 450 subjects used this possibility).

Upon logging in via their personal device (e.g. PC, laptop, tablet, smartphone), subjects entered the user interface of the game, a web-based platform. The user interface presented the subjects under the benchmark treatment with two projects, displayed side-by-side (a screenshot is displayed in Appendix A). The projects were identified by a number, described in neutral terms, and differed only in threshold and bonus. When more than two projects were presented, they were displayed with a maximum of two projects in each row. General information on the game is displayed at the top of the screen and includes (i) the number of remaining tokens in the subject's private account, (ii) the number of subjects in the group, and (iii) the game deadline: Sunday 10 p.m. In addition, specific feedback is presented for each project, including (i) total contributions by all subjects in the group, (ii) the remaining contribution gap to the threshold, (iii) the number of subjects in the group who have contributed, and (iv) the subject's own total contribution. This feedback was updated continuously so that subjects were able to make fully informed decisions. Subjects were logged off automatically after 20 minutes of inactivity.

Within three days after the end of a four-day session, payments were effectuated via a bank transfer by the research consultancy, conditional on having logged in at least once each day and filling out a short on-line survey in the week after the experiment (both conditions were announced in the invitation as well as in game instructions). This survey contained items on attitude ${ }^{6}$ game behavior, and game evaluation. The research consultancy provided us with readily available information on a wide range of demographic variables.

The value of each token was EUR 0.20. Starting with 34 tokens, subjects earned on average EUR 7.96 for an estimated time investment of, in total, about 17 minutes over four days. ${ }^{7}$

\footnotetext{
${ }^{5}$ Of course identical wording was used in all treatments. Even if the wording chosen affects behavior, there is no reason to expect that this framing affected our treatments differently.

${ }^{6}$ Based on three items from a survey designed by the Center for Philanthropic Studies to explain donation decisions, see 'Geven in Nederland 2013'; http://www.geveninnederland.nl/.

${ }^{7}$ We estimate this time investment from login behavior as follows, using the cleaned sample as described in Section 4. The average number of logins was 5.2 and the average number times a contribution was made was 4.1. If a contribution was made, the average time between login and finalizing the contribution was 200 seconds. Assuming that, conditional on having logged on, it takes an equal time to decide not to
} 


\section{Theory and predictions}

\subsection{Theoretical framework}

Consider a setting with $g \in\{1,2, \ldots, G\}$ public goods (or public good projects) and $j \in$ $\{1,2, \ldots, J\}$ players. The game starts at time $t=0$ and ends at time $t=T$. Each player has an endowment of $e_{j}$ tokens in his private account, which is his to keep, but which he can also use over the course of the game to contribute to one or more of the available $G$ public goods projects. Denote a contribution by player $j$ to good $g$ at time $t$ by $c_{j g}^{t}$. Total contributions by all players to good $g$ up to time $t$ are denoted by $C_{g}^{t}=\sum_{j} \sum_{s=1}^{t} c_{j g}^{s}$.

When a threshold contribution $\tau_{g}$ is reached at time $T$ for good $g$, a bonus $b_{g}$ is paid out to each player, independent of whether he contributed to the project, or not. No rebate implies that excess contributions $C_{g}^{T}-\tau_{g}$ are wasted. Full refund implies that any contributions of each player in a group $\left(\sum_{s=1}^{T} c_{j g}^{s}\right)$ to a good that does not reach the threshold, i.e. $C_{g}^{T}<\tau_{g}$, are returned to that player's private account. The following function denotes payoffs $\pi_{j}$ :

$$
\pi_{j}=e_{j}+\sum_{g}\left(\left\{\begin{array}{ll}
0 & \text { when } C_{g}^{T}<\tau_{g} \\
b_{g}-c_{j g}^{T} & \text { when } C_{g}^{T} \geq \tau_{g}
\end{array}\right) .\right.
$$

Payoffs are equal to the sum of endowment and good-specific payoffs. A subject's goodspecific payoff is equal to the bonus he receives minus own contributions to that good if the threshold is met, and zero otherwise, independent of own or others' contributions (an example calculation is provided in the instructions, see Appendix E). Note that this payoff specification is simpler than under the provision point mechanism where, in addition to the bonus, a marginal return is paid on total contributions $C_{g}^{T}$. With multiple public goods, removing this additional payoff increases the importance of coordination and aligns it with standard all-or-nothing crowdfunding campaigns. Not only is coordination important to obtain bonuses, coordination is also facilitated by the full refund feature (Isaac et al., 1989), which is common at major crowdfunding platforms (Wash and Solomon, 2014). Under full refund, the only cost of making a contribution to a specific good is that the remaining budget in the private account is reduced. There is no possibility that any contributed tokens are forfeited, unless the threshold is reached and the corresponding bonus is paid out. Hence, an early small contribution as a signal that players should coordinate on a particular

contribute, the average time investment was $5.2 \times 200$ seconds, or 17 minutes and 20 seconds. Note that this estimate excludes the time spent on reading the instructions upon first login and any time spent thinking about possible strategies when not logged in. 
good, is relatively cheap.

Subjects have all necessary information available in the user interface. At each moment in the game, each player is informed about $T$ (and hence $T-t$ ), the number of players who have contributed to each good, their total contributions to each good $C_{g}^{t}$, one's own (cumulative) contribution to each good $\sum_{s=1}^{t} c_{j g}^{s}$, as well as the number of tokens still available to $\operatorname{him}\left(e_{j}-\sum_{g}\left(\sum_{s=1}^{t} c_{j g}^{s}\right)\right)$. In addition, the game instructions are accessible from the user interface throughout the experiment.

In the static version of a single linear threshold public goods game with no rebate and full refund, there exist two sets of (pure-strategy) Nash equilibria. The first set contains inefficient equilibria. Such equilibria satisfy the No Deviation Constraint (Croson and Marks, 2000). That is, the threshold is not met and no single subject can make the project succeed, considering his remaining tokens, the remaining gap to the threshold, and the bonus upon success. Given full refund, any equilibrium with non-zero contributions in this set is payoff-equivalent to the zero-contributions equilibrium, which is always included in this set. For any player, contributing less would not affect payoffs while contributing more would either not affect payoffs (if such additional contribution does not fill the gap to the threshold), or would lead to a lower payoff (if such additional contribution would fill the gap, given that the gap is larger than the size of the bonus).

The second set contains efficient equilibria. In such equilibria, the threshold is exactly met with the sum of contributions being divided over the players with no player contributing more than the bonus from the good (cf. Bagnoli and Lipman, 1989; Croson and Marks, 2000). For any player, contributing more would be wasteful by no rebate, while contributing less involves not reaching the threshold and thereby foregoing the bonus.

Moving from one to multiple public goods in the static setting, contributions to the goods can be treated as separate games so that additional equilibria occur, each of which is a combination of the above equilibria for single goods. The number of equilibria is only constrained by the players' endowments and this constraint will be more strict as the number of goods increases. Efficient equilibria correspond to those where, given endowment constraints, the sum of bonuses is maximized. In our experiment, parameters for group size, endowments, and thresholds are selected such that each group can maximally reach two thresholds (as explicitly stated in the instructions), 8 which allows us to narrow down efficient equilibria to those where the two goods with the highest bonus reach their threshold.

Finally, moving from a static to a dynamic game allows all static equilibria to be

\footnotetext{
${ }^{8}$ All projects are efficient with thresholds being less than five times the bonus, while the total endowments of a group suffice to fund two goods, but never three.
} 
supported in (perfect Bayesian) equilibrium (Marx and Matthews, 2000).

\subsection{Hypotheses}

Below we motivate our treatments and formulate hypotheses based on expected game behavior. A general observation is that, given our game specification and parameterization, equilibria characterized by two thresholds having been reached payoff-dominate those with either one or none successful projects. This dominance could lead to a relatively high share of successful projects, boosted by our game features of no rebate and full refund. Coordination problems and cheap-riding, however, are likely to compromise this outcome, especially if the number of projects is larger. Compared to BEN, we expect that coordination problems in treatments SIA72 and SEED72 are resolved by signaling focal projects. As a result, we expect cheap-riding to be the dominant obstacle to reach efficient outcomes in these treatments. Similarly, fewer coordination failures should occur in SIXSEED78 than in SIX.

In the below hypotheses we will compare outcomes between different treatments based on two criteria, measured at the group level. The weaker criterion is the average level of contributions to specific projects. The stronger criterion is the average number of projects for which the threshold is reached. We will refer to both criteria together as treatments being more 'successful' (i.e. more thresholds reached and higher contributions) or less.

First, we present our hypothesis on overall game behavior, which combines three hypotheses as formulated by Bagnoli et al. (1992):

Hypothesis 1. (a) The groups will reach the threshold of exactly two goods; (b) There will not be any contributions in excess of the goods' thresholds; (c) The subjects' contributions will be individually rational, i.e. no subject contributes more to a good than the level of its bonus.

Since our game is an on-line lab-in-the-field experiment over the course of four days, we have much less control than in the laboratory. Accordingly, we expect much more noise in our data compared to e.g. Bagnoli et al. (1992).

Our hypotheses on specific differences between treatments, further discussed below, are:

Hypothesis 2. Project success is lower under SIX than under BEN.

Hypothesis 3. Seeded projects under SEED72 and SIXSEED78 are more successful than their unseeded counterparts in BEN and SIX. 
Hypothesis 4. The dominating good (i.e. $72_{18}$ ) is more successful under SIA72 than under BEN.

Regarding Hypothesis 2, the SIX treatment features an additional four goods, each of which is dominated by one of the two BEN goods. Increasing the number of available goods is expected to obstruct coordination (cf. Corazzini et al., 2015), even though two goods dominate the other four.

Regarding Hypothesis 3, the SEED72 treatment features good $92_{18}$, that receives 20 seeded tokens (and a similar increase in its threshold compared to the BEN good $72_{18}$ ). Seeding a project is expected to signal that contributions should be made to the seeded good (cf. List and Lucking-Reiley, 2002; Rondeau and List, 2008; Van de Rijt et al., 2014). Increased focus on good $72_{18}$, combined with full refund, is expected to simplify coordination on the seeded good, compared to the BEN good $72_{18}$. A similar expectation holds for the seeded good $98_{17}$ under SIXSEED78 compared to $78_{17}$ SIX. An important difference is, however, that the seeded project under SIXSEED78 is a dominated project while this is not the case under SEED72.

Regarding Hypothesis 4 , the SIA72 treatment features a 'seemingly irrelevant alternative' $72_{17}$ that is dominated by one of the other goods, $72_{18}$, for which it serves as a decoy. Adding this decoy is expected to lead to an 'attraction effect', a signal that contributions should be made to the dominating good. This effect is described and tested in a large body of research in psychological and marketing science (cf. Ariely and Wallsten, 1995). Recently, (Frederick et al., 2014) found that in less abstract choice situations, the attraction effect may disappear or even lead to a 'repulsion effect'. Since the choice situation in our experiment is featured by a high level of abstraction, we hypothesize that the attraction effect will dominate.

\section{Results}

We start the description of our results by an analysis of overall game behavior. We provide statistics related to Hypothesis 1 and we present additional contribution characteristics that are important in order to correctly interpret the game's results at the group level. Next, we assess Hypotheses 24 by comparing treatment outcomes in terms of their success.

Despite our efforts to assure full groups of active contributors (as described in Section 2.3), only 406/450 subjects participated actively with at least one login. Since at least five subjects are required to reach both goods' thresholds, for the group-level analysis, we 


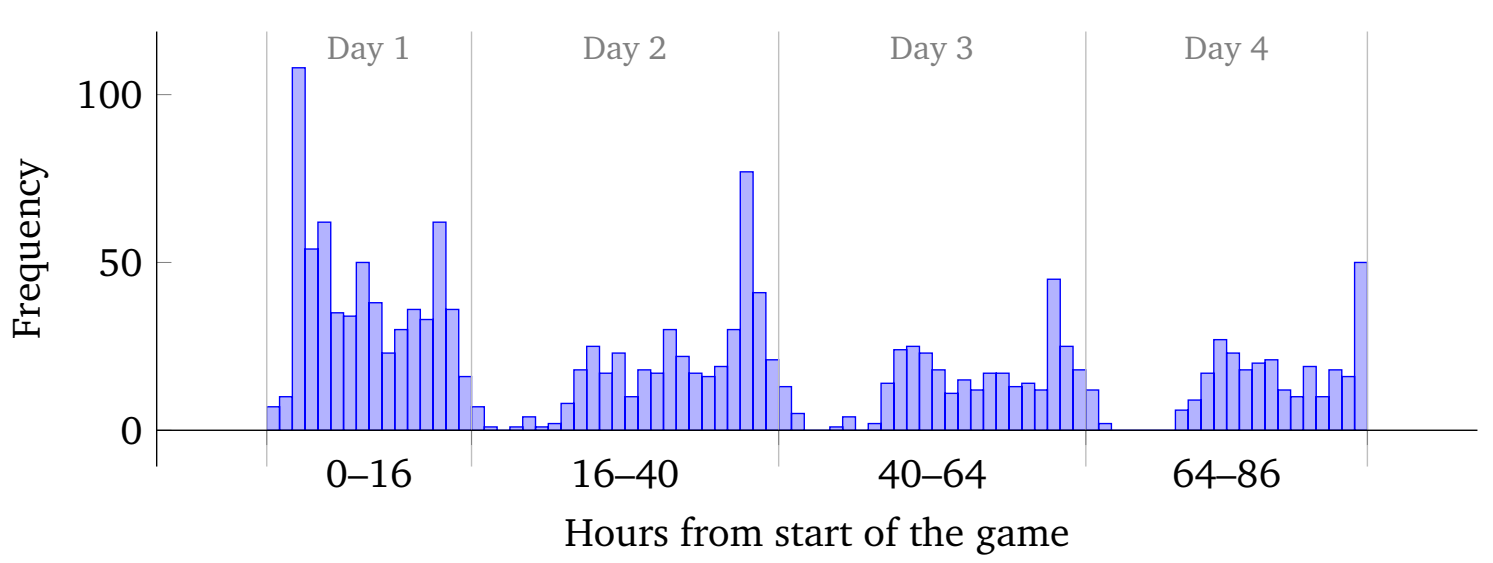

Figure 1: Investment frequency across all treatments in one-hour bins. Hour 0 corresponds to THU 8 a.m. and hour 86 corresponds to SUN 10 p.m.

drop any group that has two or more members who did not even log in once $9^{9}$ This results in 8 dropped groups out of 75: 2 for SEED72, 3 for SIA, and 3 for SIX. Group-level results and test statistics are provided for the remaining independent observations at the group level with $5 \times 15-8=67$ groups, between 12 and 15 per treatment.

\subsection{Overall game behavior (Hypothesis 1)}

In this section we provide an overview of overall game behavior which allows us to assess Hypothesis 1. Before doing so, we first illustrate the timing and levels of subjects' contributions in Figures 1 and 2. The figures reveal several tendencies that make us confident that subjects took the game seriously, despite the relatively low stakes and despite the length of the game.

Figure 1 shows the frequency of investments made across all treatments in one-hour bins. The figure shows spikes at the start of the game, and each night between 9 and 10 p.m. The figure also show a modest decrease in investment frequency over the course of the four days, which is partly explained by subjects running out of tokens: at the end of the session, $63 \%$ of subjects had invested all of their tokens. Given this constraint, there is no strong decline in interest in playing the game as the game progresses, which we interpret as subjects taking the game seriously.

Figure 2 shows the frequency of (non-aggregated) investment levels across all treatments. The figure shows spikes at focal numbers 5 and 10. The small spike at 34 indicates

\footnotetext{
${ }^{9}$ One may argue that never logging in can be interpreted as committing to not contribute anything, and hence that these 'inactive' subjects should not be dropped from the analysis. Note, however, that sometimes only small contributions are needed to reach the threshold, and hence not checking even once is only optimal if information gathering is very expensive.
} 
subjects who went all-in in one project, a seemingly irrational investment decision ${ }^{10}$ The dominance of small contributions, less than five tokens, illustrates that subjects were either signaling their interest in a specific project, trying to cheap-ride, or both. We interpret this as another signal that the game was taken seriously by most subjects.

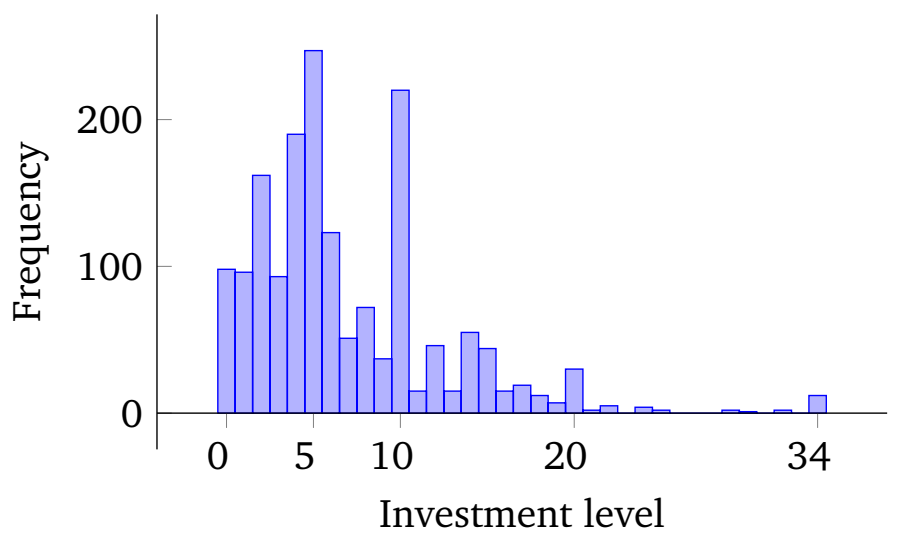

Figure 2: (Non-aggregated) investment level frequency across all treatments.

We now turn to testing Hypothesis 1 , for which we find only weak support, in line with our expectation that our data would be relatively noisy due to the lab-in-the-field setting. We start with Part (a) of Hypothesis 1 which states that groups will reach the threshold of exactly two goods. We find very limited support for this part. Only 20 of 67 groups, or $30 \%$, managed to coordinate on this efficient equilibrium. Another 37/67 (55\%), reached the threshold of exactly one good while 10/67 (15\%) reached no threshold. Recall that outcomes with no or just one successful project may constitute (inefficient) equilibria, as long as the No Deviation Constraint is satisfied. The difference in success rate with e.g.

\footnotetext{
${ }^{10}$ We assess possible causes of three types of seemingly irrational behavior by linking our experimental outcomes to subjects' login and contribution behavior as well as the survey results. The three types of seemingly irrational behavior, all of which are described in the current Section, are: (i) individual investments in one project that exceed its bonus, (ii) individual investments beyond the project threshold, and (iii) violation of the No Deviation Constraint. We test for differences between two sub-samples: subjects who made one or more of these seemingly irrational decisions and subjects who did not. Results are reported in Table 6 in Appendix B. The relevant Mann-Whitney tests indicate that the two sub-samples differ in four variables: 'Age', 'Goal: earn tokens', 'Game: instructions not clear' and 'Game: easy to play'. Subjects displaying seemingly irrational behavior were older (by approximately five years), were less focused on earning tokens, and had more difficulties in understanding the game instructions and playing the game. Note that the last three variables were measured using Likert scales, and although these differences are intuitive and statistically significant, the ordinal nature of Likert scales makes their economic impact, $0.2-0.35$ point differences in means on a 4- or 5-point scale, hard to interpret. Importantly, the two sub-samples do not differ in terms of 'Education' nor the remaining survey items on game behavior and attitude. To assess the possible impact of subjects who did not fully comprehend the game on group behavior, we repeated all regressions of Tables 4,5, while controlling for the number of subjects in each group that scored a '4' or ' 5 ' on 'Game: instructions not clear'. These robustness checks, available upon request, did not reveal any substantial differences with the results as reported in the paper. All in all, our interpretation of these results is that there is no strong evidence of a systematic cause of seemingly irrational behavior in our experiment.
} 
Bagnoli et al. (1992) who find $48 \%$ of groups coordinating on efficient outcomes. may be due to the field-setting or the lack of repetition (and hence scope for learning) in our experimental design.

Part (b) of Hypothesis 1 states that there will not be any contributions in excess of the project thresholds. We find moderate support for this part, illustrated by Figure 3 . This figure shows total investments per project, normalized with the threshold set to zero. Hence, the horizontal axis displays the number of over-invested tokens per project.

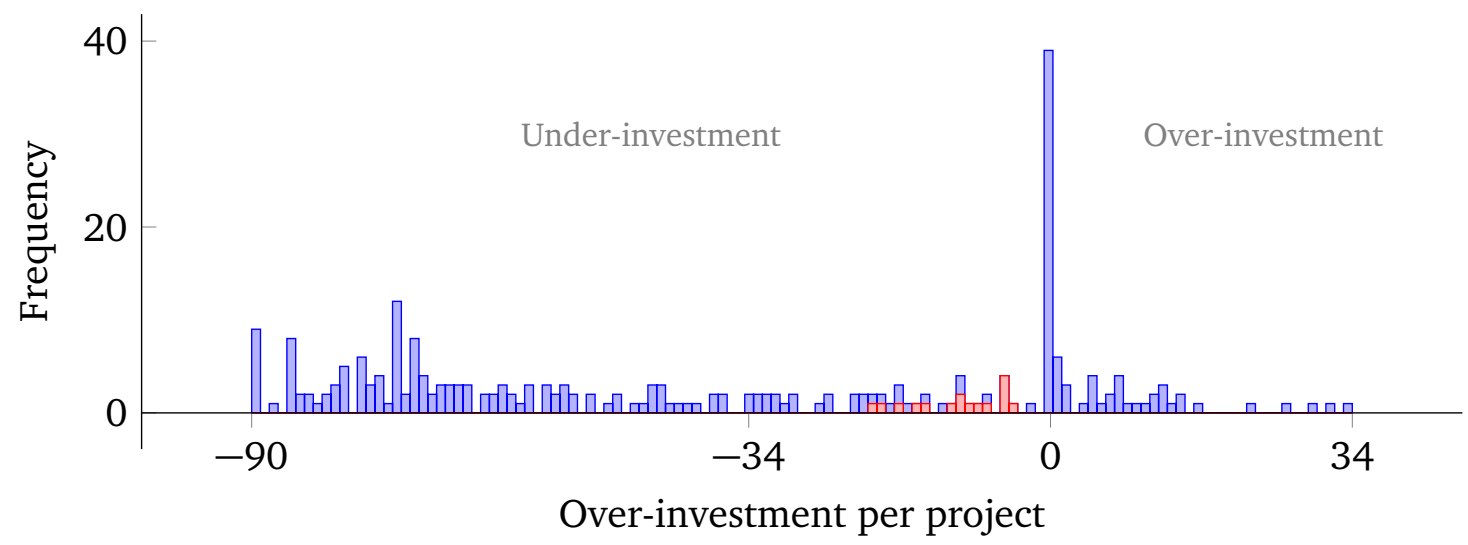

Figure 3: Frequencies of project over-investment across all treatments. Red bars mark the 16 projects that violate the No Deviation Constraint (i.e. violation implies that these groups include at least one group member who could have made the project successful).

The equilibrium behavior that was discussed in Section 3 is visible in Figure 3 , The 39 projects that make up the spike at 0 were successful without wasting any tokens, i.e. efficient equilibrium behavior. There are 177 projects to the left of 0 . These projects did not reach the threshold. Of these, 16 projects, illustrated by red bars in Figure 3, violate the No Deviation Constraint. These are projects where a single subject could have made the project successful (considering his remaining tokens, the remaining gap to the threshold, and the bonus upon success). Finally, there are 38 projects with a strictly positive over-investment, i.e. to the right of 0 . These are projects where one or more subjects displayed seemingly irrational behavior by contributing more than what was required to reach the threshold, see Footnote 10 ,

There are several possible explanations for over-investments. One is that we cannot rule out coordination failures in exactly reaching the threshold, for instance when two contributions are made shortly after one another such that feedback on others' contributions was not yet visible on the user interface, or possibly overlooked. Other alternative explanations include the possibility that subjects derive utility other than the monetary bonus from making a good successful, calculation errors, and better-safe-than-sorry contributions, see 
Footnote 10. All in all, 200 of 254 projects, or 79\%, have outcomes that are predicted by equilibrium behavior. Related to Part (b) of Hypothesis 1, we find that 38 of 254 projects, or $15 \%$, feature contributions in excess of the projects' thresholds.

Part (c) of Hypothesis 1 states that no subject contributes more to a good than the level of its bonus. We find weak support for this part. Only 68\% of subjects (i.e. 196 of 290 subjects who logged in at least four times) displays rational behavior in terms of contributions. However, as with Part (b) of Hypothesis 1, it is well possible that part of the seemingly irrational behavior by the other $32 \%$ is driven by alternative explanations. Such explanations receive suggestive support from the contribution behavior of the 94 subjects who contributed more to a good than the level of its bonus. Of these, $60 \%$ overcontributed just 4 tokens or less while 14\% over-contributed exactly 10 tokens. We interpret these over-contributions as possibly arising from calculation errors or better-safe-thansorry contributions. We provide more background information on such explanations in Footnote 10 .

The results on individually rational contribution behavior are partly illustrated by Figure 4, which shows payoff in tokens per subject. Payoffs lower than 34, subjects' initial endowments, indicate that a seemingly irrational investment was made. Small spikes at 18 and 24 include subjects who went all-in in one successful BEN good, and received the bonus of, respectively, 18 or 24 tokens. The spike at 34 includes subjects who did not invest or whose investments were not successful and got refunded so they ended up with their initial endowment of 34 tokens. The spike at 42 includes subjects who went all-in in two successful BEN goods, and received two bonuses that sum up to $18+24=42$ tokens. All payoffs higher than, approximately, $34-(72+84) / 6+(18+24)=50$ (and 45 for groups of 5 ) include subjects who were either lucky with other group members contributing relatively more or they were successfully cheap-riding.

Combining the results for the three parts we only find weak support for Hypothesis 1 . We do find evidence, however, that subjects took the game seriously, despite the low stakes and despite the length of the game. This allows us to continue with the assessment of treatment results.

\subsection{Treatment results (Hypotheses 2-4)}

In this section we compare treatment outcomes in terms of their success in order to assess Hypotheses 2 4. We first provide graphical evidence of treatment impacts in Figure 5. The top panel of Figure 5 shows the average number of successful projects per group across all treatments. At first sight there appear to be some stark differences between treatments, not 


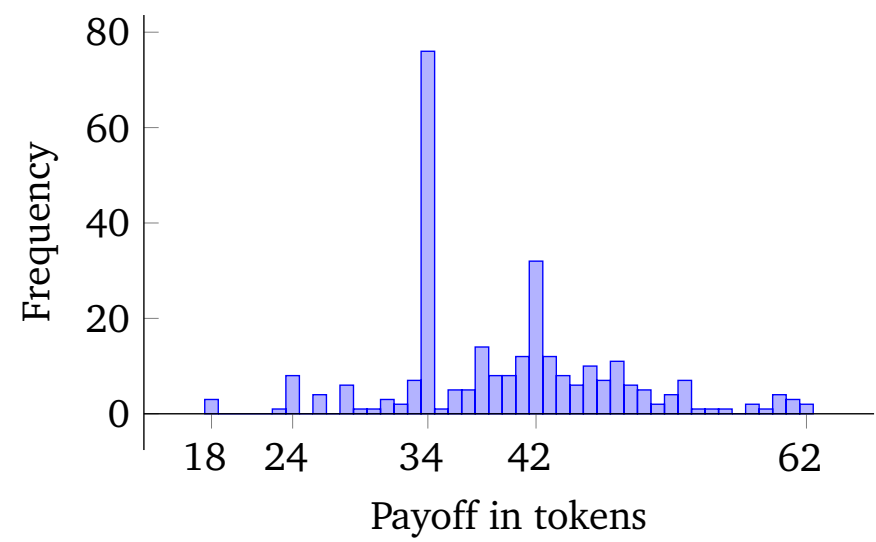

Figure 4: Payoff frequency in tokens across all treatments.

so much in the total number of successful projects, but rather in the distribution of success over the different projects. Under BEN, subjects appear to have a slight preference for the more efficient $84_{24}$ compared to $72_{18}$. Consistent with our expectations, SEED72 reverses the preference, despite the fact that $84_{24}$ remains the more efficient project. Surprisingly, SIA72 strengthens the (relative) preference for $84_{24}$, drawing contributions from $72_{18}$. SIX and SIXSEED78 do not really affect the relative preference for $84_{24}$ over $72_{18}$. They do, however, worsen coordination as displayed by quite a number of successful (dominated) projects other than $84_{24}$ or $72_{18}$.

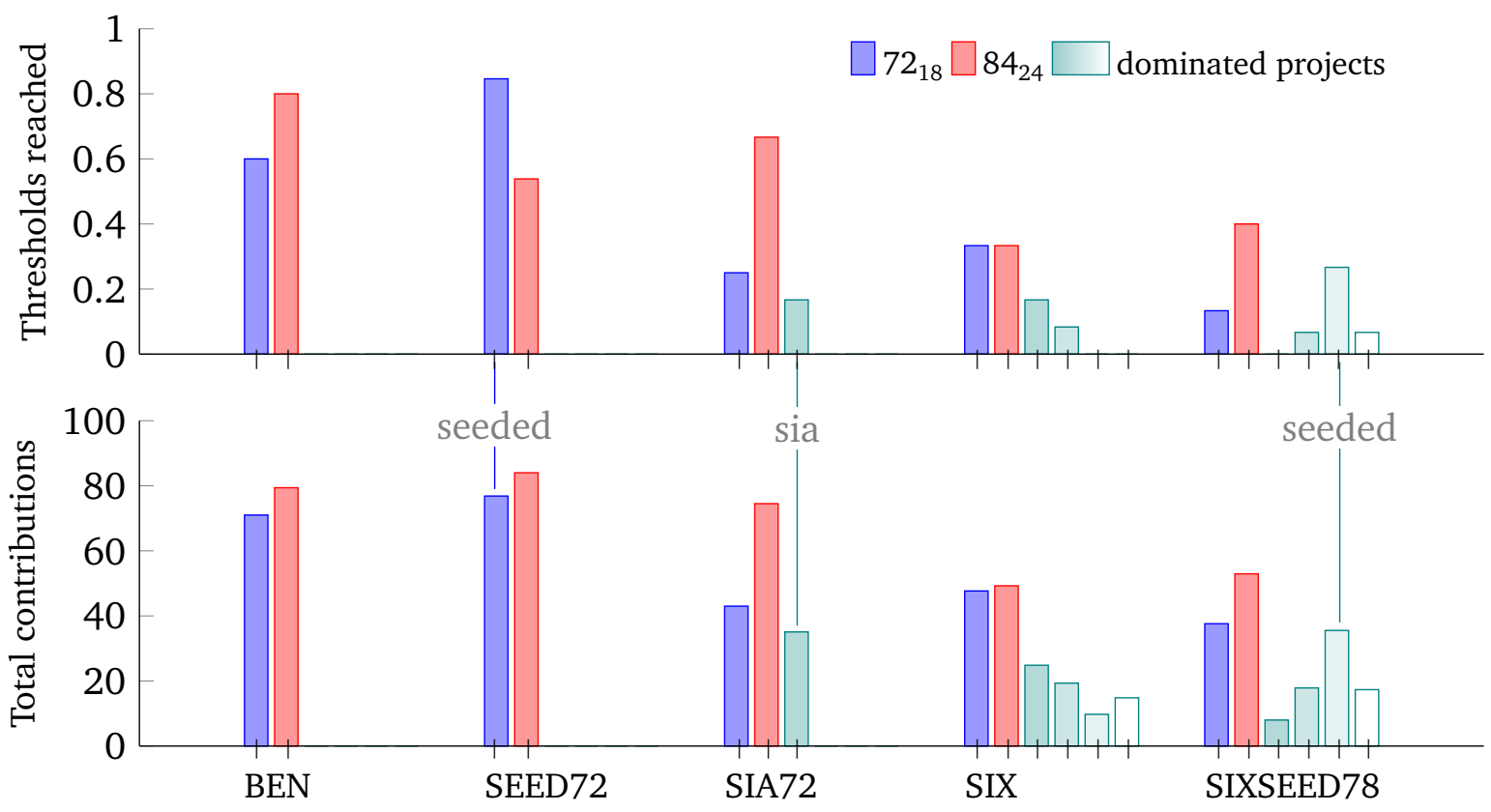

Figure 5: Average number of thresholds reached (top panel) and total contributions (bottom panel) across treatments, separated by project. See Table 1. 
The bottom panel of Figure 5 shows the related average total contributions per group across treatments. Similar to the total number of successful projects, total contributions (i.e. the aggregate of contributions to all projects) do not appear to differ much across treatments. Most of the variation that occurred in the top panel is also visible in the bottom panel. Nevertheless, there are subtle differences between the two panels, driven by whether or not changes in total contributions materialize into changes in the number of thresholds reached. One notable difference is the relatively large number of successful seeded projects for SEED72 in the top panel relative to its received contributions in the bottom panel. Another difference are the non-zero contributions in the bottom panel for some dominated projects under SIX and SIXSEED78 that do not materialize into successful projects in the top panel.

In Table 2 we aggregate the data from Figure 5 at project-level in order to show total project success and its implications for welfare. To keep welfare comparisons across treatments straightforward, we present individual welfare as measured by received bonuses from successful projects, ignoring impacts from group size and excess contributions. The first two rows show that while contributions are constant across treatments, coordination failures cause a lower number of thresholds reached for the three treatments with more than two projects as compared to BEN. Mann-Whitney rank-sum tests show that this difference with BEN is significant only for SIX $(z=1.64, p=0.10)$ and SIXSEED78 $(z=2.24$, $p=0.03)$, but not for SEED72 $(z=0.21, p=0.83)$ or SIA72 $(z=1.06, p=0.29)$. The last row shows that this effect on the number of thresholds reached translates into lower individual welfare. Again, Mann-Whitney rank-sum tests show that this difference with BEN is significant only for SIX $(z=1.83, p=0.07)$ and SIXSEED78 $(z=2.69, p=0.01)$, but not for SEED72 $(z=0.83, p=0.40)$ or SIA72 $(z=1.30, p=0.20)$.

Table 2: Average number of thresholds reached, total contributions, and individual welfare across treatments. See Figure 5 ,

\begin{tabular}{lccccc}
\hline & BEN & SEED72 & SIA72 & SIX & SIXSEED78 \\
\hline Thresholds reached & 1.40 & 1.38 & 1.08 & 0.92 & 0.93 \\
Total contributions & 150.4 & 160.8 & 152.6 & 165.7 & 169.3 \\
Individual welfare & 30 & 28.2 & 23.3 & 18.5 & 19.5 \\
\hline
\end{tabular}

We proceed with a statistical analysis of treatment differences.

Hypothesis 2 We start with Hypothesis 2, stating that project success is lower under SIX than under BEN. We assess this hypothesis using the regressions presented in Table 3. In this table we provide an analysis of treatment effects on total contributions and number of 
thresholds reached. The dependent variable in the OLS regression Models (1) and (3) is total contributions, measured as the sum of contributions to all available projects, at the group level. The dependent variable in ordered probit Models (2) and (4) is the number of project thresholds reached, measured as the sum of thresholds reached of all available projects, at the group level. Recall from Section 3 that our parameter selection is such that each group can maximally reach two thresholds. Hence, the value of the dependent variable in these models is 0,1 , or 2 . Both dependent variables are regressed on treatment dummies and the number of subjects per group (recall that groups consist of 5 or 6 subjects for all treatments). Models (1) and (2) consider all available projects while Models (3) and (4) focus on $84_{24}$ and $72_{18}$ (the two BEN projects) only, since these are the two dominant projects across all treatments.

For Models (2) and (4), sign and significance of the coefficients for the SIX dummy indicate strong support for Hypothesis 2, in terms of number of thresholds reached. Model (3) also provides support, as it shows that the total number of tokens contributed to the two key projects, $72_{18}$ and $84_{24}$, is also significantly smaller in SIX than in BEN. Model (1) regressing total contributions to all available projects at the group level - is the exception, displaying a positive sign - but this does not result in more projects ending up being successful, as shown by Model (2). In addition, the number of subjects per group is positively related to project success. We find that having a sixth group member makes a substantial difference in total contributions per group, which translates into an increase in the probability of reaching an additional threshold by about 20\%-points. 11

The parametric results of Table 3 are confirmed by Mann-Whitney rank-sum tests. Based on all available projects, total contributions are higher under SIX compared to BEN $(z=-1.59, p=0.11)$, while the number of thresholds reached is lower under SIX compared to BEN $(z=1.64, p=0.10)$. Focusing on the two BEN projects, total contributions are lower under SIX compared to BEN $(z=4.05, p=0.00)$, while the number of thresholds reached is also lower under SIX compared to BEN $(z=2.83, p=0.00)$.

Going beyond Hypothesis 2, Table 3 shows that identical results occur for the other two treatments with more than two projects, i.e. SIA72 and SIXSEED78. This result confirms the severity of coordination problems that occur when multiple projects are available (cf. Corazzini et al., 2015). Assessing SIA72, SIX, and SIXSEED78 combined, increasing the number of project increases total contributions, but decreases contributions to the two dominating projects. This dispersion of contributions leads to a decrease in the number of thresholds reached. Our interpretation of this result is in line with our prediction:

\footnotetext{
${ }^{11}$ This $20 \%$-point increase in probability is computed based on average marginal effects for Models (2) and (4).
} 
Table 3: Project success as measured by total contributions and number of thresholds reached.

\begin{tabular}{|c|c|c|c|c|}
\hline & \multicolumn{2}{|c|}{ All projects } & \multicolumn{2}{|c|}{ BEN projects only } \\
\hline & $\begin{array}{c}\text { (1) } \\
\text { Contributions }\end{array}$ & $\begin{array}{c}\text { (2) } \\
\text { Thresholds }\end{array}$ & $\begin{array}{c}\text { (3) } \\
\text { Contributions }\end{array}$ & $\begin{array}{c}\text { (4) } \\
\text { Thresholds }\end{array}$ \\
\hline SEED72 & $\begin{array}{c}3.180 \\
(7.694)\end{array}$ & $\begin{array}{c}-0.318 \\
(0.466)\end{array}$ & $\begin{array}{c}6.733 \\
(8.696)\end{array}$ & $\begin{array}{c}-0.247 \\
(0.474)\end{array}$ \\
\hline SIA72 & $\begin{array}{c}0.643 \\
(7.772)\end{array}$ & $\begin{array}{c}-0.745 \\
(0.469)\end{array}$ & $\begin{array}{r}-33.69^{* * *} \\
(8.785)\end{array}$ & $\begin{array}{c}-1.189^{* *} \\
(0.492)\end{array}$ \\
\hline SIX & $\begin{array}{l}13.73^{*} \\
(7.772)\end{array}$ & $\begin{array}{c}-1.085^{* *} \\
(0.473)\end{array}$ & $\begin{array}{r}-54.27^{* * *} \\
(8.785)\end{array}$ & $\begin{array}{c}-1.791^{* * *} \\
(0.530)\end{array}$ \\
\hline SIXSEED78 & $\begin{array}{c}20.92^{* * *} \\
(7.332)\end{array}$ & $\begin{array}{c}-0.917^{* *} \\
(0.445)\end{array}$ & $\begin{array}{r}-58.82^{* * *} \\
(8.287)\end{array}$ & $\begin{array}{c}-1.995^{\text {*** }} \\
(0.513)\end{array}$ \\
\hline \# Subjects/group & $\begin{array}{c}30.80^{* * * *} \\
(5.077)\end{array}$ & $\begin{array}{l}1.113^{* * *} \\
(0.321)\end{array}$ & $\begin{array}{l}15.74^{* * *} \\
(5.738)\end{array}$ & $\begin{array}{l}0.929^{* * *} \\
(0.326)\end{array}$ \\
\hline Constant & $\begin{array}{l}-20.03 \\
(28.57)\end{array}$ & & $\begin{array}{c}63.30^{*} \\
(32.29)\end{array}$ & \\
\hline cut1 & & $\begin{array}{l}4.336^{* *} \\
(1.723)\end{array}$ & & $\begin{array}{r}3.045^{*} \\
(1.757)\end{array}$ \\
\hline cut2 & & $\begin{array}{l}6.280^{* * *} \\
(1.813)\end{array}$ & & $\begin{array}{l}5.354^{* * *} \\
(1.847)\end{array}$ \\
\hline Observations & 67 & 67 & 67 & 67 \\
\hline
\end{tabular}

${ }^{*} p<0.10,{ }^{* *} p<0.05,{ }^{* * *} p<0.01$

Coefficient estimates from OLS regression models in (1) and (3) and ordered probit models in (2) and (4) (and standard errors in parentheses). All models are at the group level. Contributions in (1) and (3) equal the sum of contributions to all available projects (1) or BEN projects only (3). Similarly, thresholds in (2) and (4) equal the sum of thresholds reached. Treatment names represent dummy variables, with BEN as the omitted reference treatment.

coordination problems lead to inefficiencies.

Hypothesis 3 Next, we assess Hypothesis 3, stating that seeded projects under SEED72 and SIXSEED78 are more successful than their unseeded counterparts under, respectively, BEN and SIX. We assess this hypothesis using the regressions presented in Table 4. In this table we build on Table 3 by analyzing treatment effects on total contributions and number of thresholds reached. The difference is that we now focus on the target project of each treatment. Recall from Table 1 that the target project for SEED72 is project $72_{18}$ (or $92_{18}$ when seeded) and the target project for SIXSEED78 is project $78_{17}$ (or $98_{17}$ when seeded). 
Since the target project under SEED72 and SIA72 is identical, we also include a treatment dummy for SIA72 in the regressions of Table 4 and refer to the same table when assessing Hypothesis 4 below. Total contributions and number of thresholds reached are regressed on the relevant treatment dummies and the number of subjects per group. We exclude a model that regresses thresholds reached for the target project under SIXSEED78 since this treatment is a perfect predictor of thresholds reached, as illustrated by the top panel of Figure 5 .

Table 4: Treatment impacts on project success of the target project.

\begin{tabular}{|c|c|c|c|}
\hline & \multicolumn{2}{|c|}{ Project $72_{18}$} & \multirow{2}{*}{$\begin{array}{c}\text { Project } 78_{17} \\
(3) \\
\text { Contributions }\end{array}$} \\
\hline & $\begin{array}{c}\text { (1) } \\
\text { Contributions }\end{array}$ & $\begin{array}{c}\text { (2) } \\
\text { Thresholds }\end{array}$ & \\
\hline SEED72 & $\begin{array}{c}5.937 \\
(6.751)\end{array}$ & $\begin{array}{c}0.681 \\
(0.547)\end{array}$ & \\
\hline SIA72 & $\begin{array}{r}-27.98^{* * *} \\
(6.762)\end{array}$ & $\begin{array}{r}-0.957^{*} \\
(0.518)\end{array}$ & \\
\hline SIXSEED78 & & & $\begin{array}{c}26.38^{* *} \\
(10.57)\end{array}$ \\
\hline \# Subjects/group & $\begin{array}{c}-0.386 \\
(5.828)\end{array}$ & $\begin{array}{c}0.316 \\
(0.456)\end{array}$ & $\begin{array}{r}5.115 \\
(10.51)\end{array}$ \\
\hline Constant & $\begin{array}{c}73.14^{* *} \\
(32.56)\end{array}$ & $\begin{array}{c}-1.491 \\
(2.537)\end{array}$ & $\begin{array}{c}-18.81 \\
(59.20)\end{array}$ \\
\hline Observations & 40 & 40 & 27 \\
\hline
\end{tabular}

${ }^{*} p<0.10,{ }^{* *} p<0.05,{ }^{* * *} p<0.01$

Coefficient estimates from OLS regression models in (1) and (3) and probit model in (2) (and standard errors in parentheses). All models are at the group level. The target project in (1) and (2) is project $72_{18}$ (or $92_{18}$ when seeded). The target project in (3) is project $78_{17}$ (or $98_{17}$ when seeded). Contributions in (1) and (3) equal the sum of contributions to the target project. Thresholds in (2) equals the sum of thresholds reached of the target project. Treatment names represent dummy variables, with BEN as the omitted reference treatment for (1) and (2) and SIX as the omitted reference treatment for (3).

In addition to this perfect prediction, sign and significance of the coefficient for the SIXSEED78 dummy in Model (3) indicates strong support for Hypothesis 3 . The coefficients for the SEED72 dummy in Models (1) and (2), however, indicate no effect of seeding under this treatment. These results are robust to alternative specifications of the dependent variable. Tables 7 and 8 in Appendix $\mathrm{C}$ confirm the results of Table 4 using either the difference or the ratio of success of the target project relative to the other available projects as the dependent variable. The only difference with Table 4 is that measuring success in relative terms reveals a positive impact of seeding under SEED72, not in terms of 
contributions, but only in terms of thresholds reached, an effect that is also observable in Figure 5. The results of Table 4 are also confirmed by non-parametric Mann-Whitney rank-sum tests. For the seeded good under SEED72, we find that total contributions to $92_{18}$ under SEED72 do not differ statistically from those to $72_{18}$ under BEN $(z=-1.33$, $p=0.18)$ and the same holds for the number of thresholds reached $(z=-1.41, p=0.16)$. For the seeded good under SIXSEED78, we find that total contributions to $92_{18}$ under SEED72 are higher than those to $78_{17}$ under SIX $(z=-2.75, p=0.01)$ and the same holds for the number of thresholds reached $(z=-1.90, p=0.06)$. Combined, we find moderate support for a seeding effect; weaker under SEED72 and stronger under SIXSEED78.

Seeding appears to work with six available projects but not with two, despite the seeded project being dominated under SIXSEED78 but not under SEED72. A straightforward explanation for this difference is that the multitude of available projects and their similarity in terms of characteristics (see Table 1), may trigger boundedly rational behavior. If so, subjects may pay less or no attention to specific features of the problem as in e.g. Gabaix (2014). Under these conditions, choosing a seeded project is an easy default (Carroll et al., 2009). Such default behavior is not induced when the required attention to make the decision is low, such as when only two projects have to be compared. In that case, subjects will make a fully-informed comparison of potential payoffs. In line with results found by Corazzini et al. (2015), in doing so they ignore the possible coordination benefits offered by focusing on the seeded project. Subjects in our sample have a slight preference for the more efficient project $84_{24}$ (see the BEN results in Figure 5), which was the reason for seeding the less efficient project $72_{18}$ under SEED72. Since the seeded project is still the least efficient, subjects may ignore this seeding. On top of this, recall that our selection of parameters for group size, endowments, and thresholds allows each group to maximally reach two thresholds. When faced with two available projects, subjects who expect to reach two thresholds may therefore dismiss the seeding as irrelevant.

Hypothesis 4 Finally, we assess Hypothesis 4, stating that the dominating good $72_{18}$ is more successful under SIA72 than under BEN. Again, we can use the regressions presented in Table 4. Sign and significance of the coefficient for the SIA72 dummy in models (1) and (2) of Table 4 indicate a negative effect of adding a seemingly irrelevant project on project success of project $72_{18}$. Hence, we find no support for Hypothesis 4. Similar to the impact of seeding, this result is robust to alternative specifications of the dependent variable. Tables 7 and 8 in Appendix C confirm the results of Table 4. The only difference with Table 4 is that the negative impact of SIA on thresholds reached is not statistically significant when success is measured in relative terms. The results of Table 4 are confirmed by non- 
parametric Mann-Whitney rank-sum tests, which provide no support for our hypothesis either. The number of thresholds reached for $72_{18}$ under SIA72 is lower than under BEN $(z=1.79, p=0.07)$, and the same holds for total contributions $(z=2.85, p=0.00)$. All in all we find a strong effect of adding the seemingly irrelevant project, but the effect goes in the unexpected direction. Combined, we find no support for Hypothesis 4.

We thus find that adding a seemingly irrelevant project gives rise to a repulsion rather than an attraction effect. Importantly, the presence of repulsed subjects does not cause an increase in success of project $84_{24}$, but rather causes some success for the irrelevant alternative itself. Given the state of the literature on this effect, and especially the lack of experimental work on the repulsion effect, we can only speculate that there is some type of 'black sheep' effect at play, where adding the irrelevant alternative makes the competitor option more unique (Frederick et al., 2014).

Summarizing our results, we find that (a) adding projects strongly decreases overall project success, even when the added projects are dominated; (b) providing a project with seed money may strongly increase project success (but not unequivocally); and (c) adding a seemingly irrelevant project that serves as a decoy has a strong effect, but not in the expected direction: a repulsion effect occurs where an attraction effect was expected.

\section{A conservation experiment}

In order to verify our seeding and repulsion results in a setting closer to the field, as well as closer to possible applications, we conducted a follow-up framed field experiment. We teamed up with a Dutch charity, Natuurmonumenten, an environmental NGO that is the largest private land owner in the Netherlands. 12 We ran three more sessions of our experiment that differed in one important aspect from our earlier experiment. This difference is that we replaced the abstract projects from our earlier experiment by actual nature conservation projects. Upon reaching a project threshold, the bonus of the project is not paid out in tokens to the group members but rather the tokens are transferred to money and paid out to the charity project. This change brings about two implications. One is that we move from a monetary bonus to an in-kind bonus, the size of which is described to the subjects as representing a 'nature development score'. The numerical values attached to this score are identical to the values of the bonuses in the earlier experiment. The second is that we move from a local public good (i.e. only group members benefit) to a global public good (i.e. society as a whole benefits from any use and non-use values derived from

\footnotetext{
${ }^{12}$ See http://www.natuurmonumenten.nl/.
} 
the conserved nature area, cf. Blackwell and McKee, 2003).

In order to keep differences in instructions and user interface as small as possible, the conservation projects were described in general terms, without revealing their name or location, while all parameter values for projects' threshold and bonus are kept constant between the two experiments, with the bonus now referring to the 'nature development score' ${ }^{13}$ The conservation projects were described to the subjects as "targeting development of new nature and contributing to the overall quality of nature in the Netherlands".

Three treatments were repeated in this conservation experiment: BEN, SEED72, and SIA. The two treatments with six projects were not repeated since corresponding nature conservation projects could not be credibly included, given the fixed parameters for thresholds and nature conservation scores. Sampling and procedures were identical to the earlier experiment. The experiment took place in three sessions, each lasting from Thursday 8 a.m. to Sunday 10 p.m., and were conducted in the period of May-June 2017. The conservation experiment had a lower share of active subjects; 224/270 subjects participated actively with at least one login. As a result, 10 out of 54 groups had two or more subjects who did not log in even once, and these groups were dropped from the analysis: 4 for BEN, 4 for SEED72, and 2 for SIA.

Overall game behavior was roughly similar to the earlier experiment ${ }^{14}$ The one main difference is the lower share of successful projects. This difference is illustrated in Figure 6 that provides graphical evidence of treatment impacts in the conservation experiment. Similar to Figure 5, the top panel of Figure 6 shows the average number of successful projects per group across all treatments, while the bottom panel shows the related average total contributions per group across treatments. Comparing the two experiments, total contributions in the conservation experiment are slightly lower (on average -17\%, MannWhitney $z=3.55, p=0.00$ ) while thresholds reached are much lower (on average $-58 \%$, Mann-Whitney $z=4.29, p=0.00$ ).

We proceed with a statistical analysis of treatment differences, repeating Models (1) and (2) of Table 4 for the conservation experiment. In Table 5 we analyze treatment effects on total contributions and number of thresholds reached, focusing on project $72_{18}$ (or $92_{18}$ when seeded), the target project for SEED72 and SIA. We find qualitatively similar results of project success in the conservation experiment. The coefficients for the SEED72 dummy in Models (1) and (2) indicate no effect of seeding under this treatment, confirming our result for Hypothesis 3 under the earlier experiment. Sign and significance of the coefficient for the SIA72 dummy in models (1) and (2) indicate a negative effect of adding a seemingly

\footnotetext{
${ }^{13}$ The two conservation projects that were actually used are Soesterveen and Vlijmers Ven.

${ }^{14}$ See Figures 8,10 in Appendix D.
} 


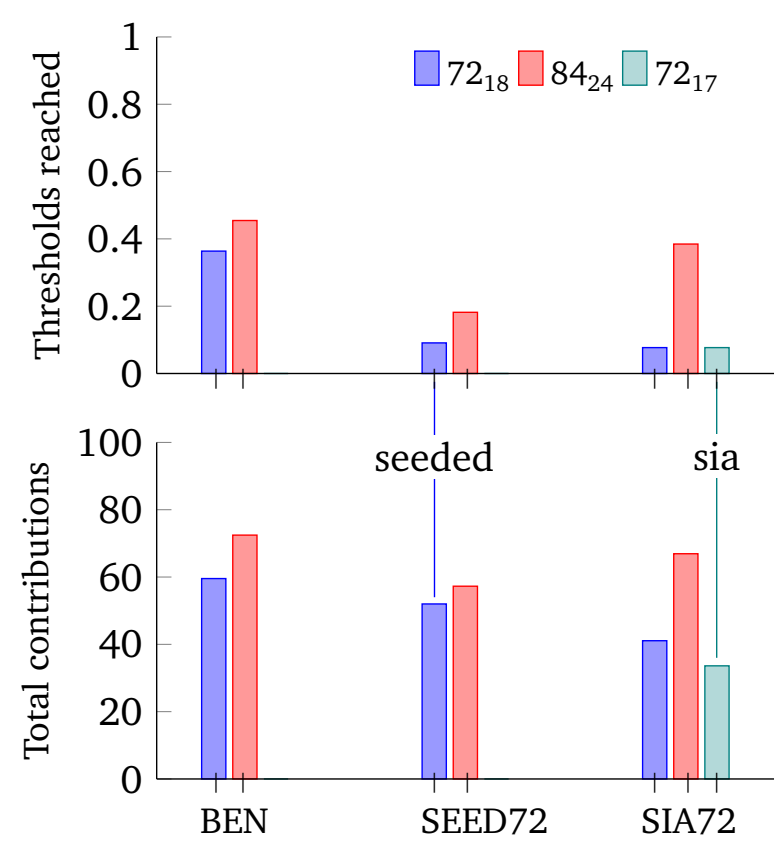

Figure 6: Results of the conservation experiment: Average number of thresholds reached (top panel) and total contributions (bottom panel) across treatments, separated by project. Compare Figure 5 .

irrelevant project on project success of project $72_{18}$, confirming our result for Hypothesis 4 under the earlier experiment.

Similar to the earlier experiment, these results are robust to alternative specifications of the dependent variable. Tables 9 and 10 in Appendix C confirm the results of Table 5 . The only difference, also found in the earlier experiment, is that the negative impact of SIA on thresholds reached is not statistically significant when success is measured in relative terms.

All in all, the conservation experiment confirms the results of our earlier experiment in terms of general investment behavior, the impact of seeding and adding a seemingly irrelevant project. This similarity in treatment impacts across the two experiments occurs despite the lower success rate in the conservation experiment, both in terms of contributions and in terms of thresholds reached. It suggests that the data patterns found are not random and reveal crowdfunding behavior as it may be observed in reality as well. This would, among other things, imply a substantial repulsion effect when adding seemingly irrelevant projects and strong effects of seeding. We attribute the lower success rate in the conservation experiment to the changed nature of the bonus under the conservation experiment. The bonus is now in-kind rather than monetary and global rather than local, decreasing individual incentives to reach the threshold. 
Table 5: Results of the conservation experiment: Treatment impacts on project success of the target project. Compare Table 4.

\begin{tabular}{|c|c|c|}
\hline & \multicolumn{2}{|c|}{ Project $72_{18}$} \\
\hline & $\begin{array}{c}\text { (1) } \\
\text { Contributions }\end{array}$ & $\begin{array}{c}\text { (2) } \\
\text { Thresholds }\end{array}$ \\
\hline SEED72 & $\begin{array}{r}-7.545 \\
(8.491)\end{array}$ & $\begin{array}{c}-1.342 \\
(0.817)\end{array}$ \\
\hline SIA72 & $\begin{array}{r}-20.30^{* *} \\
(8.199)\end{array}$ & $\begin{array}{c}-1.633^{* *} \\
(0.828)\end{array}$ \\
\hline \# Subjects/group & $\begin{array}{l}16.39^{* *} \\
(7.301)\end{array}$ & $\begin{array}{c}1.514^{* *} \\
(0.698)\end{array}$ \\
\hline Constant & $\begin{array}{c}-26.89 \\
(38.96)\end{array}$ & $\begin{array}{c}-8.365^{* *} \\
(3.716)\end{array}$ \\
\hline Observations & 35 & 35 \\
\hline \multicolumn{3}{|c|}{$\begin{array}{l}{ }^{*} p<0.10,{ }^{* *} p<0.05,{ }^{* * *} p<0.01 \\
\text { Coefficient estimates from OLS regression model in (1) and probit model in (2) (and standard errors in } \\
\text { parentheses). All models are at the group level. The target project in (1) and (2) is project } 72_{18} \text { (or } 92_{18} \\
\text { when seeded). Contributions in (1) equal the sum of contributions to the target project. Thresholds in (2) } \\
\text { equals the sum of thresholds reached of the target project. Treatment names represent dummy variables, } \\
\text { with BEN as the omitted reference treatment. }\end{array}$} \\
\hline
\end{tabular}

\section{Conclusion}

We assess the impact of crowdfunding design on the success of crowdfunded public goods using both a lab-in-the-field experiment and a framed field experiment. Specifically, we analyze whether mechanisms that signal focal projects can be used to increase project success. We find that (a) adding projects obstructs coordination thereby decreasing project success of target projects, even when the added projects are dominated; (b) providing a project with seed money may strongly increase project success (but not unequivocally); and (c) adding a seemingly irrelevant project that serves as a decoy has a strong effect, but not in the expected direction: a repulsion effect occurs where an attraction effect was expected.

A positive implication of these results is that mechanisms such as seed money and seemingly irrelevant projects may be used to mitigate coordination problems in civic crowdfunding. This option is relevant both for the crowdfunding platforms that seek to maximize success rates as well as fund-raisers that aim to amass investments to their own project. A negative implication is that the same mechanisms can be used to draw funding away from competing projects, even if these were dominant, possibly leading to 
socially inefficient outcomes. In our experiment this possibility showed up in treatment SIXSEED78 where a dominated project was seeded, drawing away contributions from the other projects. We also found in our data cases of 'unintended seeding', i.e. one subject making a seemingly irrational investment decisions early in the experiment, which may affect others' contribution decisions. In fact, in all 11 cases where a dominated projects reached the threshold (i.e. project $72_{17}$ under SIA72 or any of the four dominated projects under SIX and SIXSEED78), a large contribution (13.3 tokens on average) was made at the start of the game $\left(2.7^{\text {th }}\right.$ contribution from the start of the experiment on average), which made these projects undominated and eventually successful.

All in all, our results show that investment behavior on crowdfunding websites can be directed in order to mitigate coordination problems. Our lab-in-the-field results partly confirm earlier lab findings, they point to the scope for design alternatives that improve coordination, and give further support for crowdfunding as a promising mechanism for the private provision of public goods. 


\section{References}

Agrawal, J., C. Catalini, and A. Goldfarb (2014). Some simple economics of crowdfunding. In J. Lerner and S. Stern (Eds.), Innovation Policy and the Economy. Chicago: University of Chicago Press.

Alekseev, A., G. Charness, and U. Gneezy (2017). Experimental methods: When and why contextual instructions are important. Journal of Economic Behavior and Organization 134, 48-59.

Ariely, D. and T. S. Wallsten (1995). Seeking subjective dominance in multidimensional space: An explanation of the asymmetric dominance effect. Organizational Behavior and Human Decision Processes 63(3), 223-232.

Bagnoli, M., S. Ben-David, and M. McKee (1992). Voluntary provision of public goods: The multiple unit case. Journal of Public Economics 47(1), 85-106.

Bagnoli, M. and B. Lipman (1989). Provision of public goods: Fully implementing the core through private contributions. Review of Economic Studies 56(4), 583-601.

Belleflamme, P., N. Omrani, and M. Peitz (2015). The economics of crowdfunding platforms. Information Economics and Policy 33, 11-28.

Blackwell, C. and M. McKee (2003). Only for my own neighborhood?: Preferences and voluntary provision of local and global public goods. Journal of Economic Behavior and Organization 52(1), 115-131.

Bøg, M., H. Harmgart, S. Huck, and A. Jeffers (2012). Fundraising on the internet. Kyklos 65(1), 18-30.

Cadsby, C. and E. Maynes (1999). Voluntary provision of threshold public goods with continuous contributions: Experimental evidence. Journal of Public Economics 71 (1), $53-73$.

Carroll, G., J. Choi, D. Laibson, B. Madrian, and A. Metrick (2009). Optimal defaults and active decisions. Quarterly Journal of Economics 124(4), 1639-1674.

Charbit, C. and G. Desmoulins (2017). Civic crowdfunding: A collective option for local public goods? OECD Regional Development Working Paper 2017/02.

Chovanculiak, R. and M. Hudik (2017). Private provision of public goods via crowdfunding. Forthcoming in Journal of Institutional Economics. 
Corazzini, L., C. Cotton, and P. Valbonesi (2015). Donor coordination in project funding: Evidence from a threshold public goods experiment. Journal of Public Economics 128, 16-29.

Cornes, R. and T. Sandler (1996). The Theory of Externalities, Public Goods, and Club Goods, 2nd Edition. Cambridge: Cambridge University Press.

Crosetto, P. and T. Regner (2014). Crowdfunding: Determinants of success and funding dynamics. Jena Economic Research Papers 2014-035, Friedrich-Schiller-University Jena.

Croson, R. and M. Marks (2000). Step returns in threshold public goods: A meta-and experimental analysis. Experimental Economics 2(3), 239-259.

Davies, R. (2015). Three provocations for civic crowdfunding. Information, Communication and Society 18(3), 342-355.

Devaraj, S. and P. Patel (2016). Influence of number of backers, goal amount, and project duration on meeting funding goals of crowdfunding projects. Economics Bulletin 36(2), 1242-1249.

Dorsey, R. (1992). The voluntary contributions mechanism with real time revisions. Public Choice 73(3), 261-282.

Duffy, J., J. Ochs, and L. Vesterlund (2007). Giving little by little: Dynamic voluntary contribution games. Journal of Public Economics 91(9), 1708-1730.

Frederick, S., L. Lee, and E. Baskin (2014). The limits of attraction. Journal of Marketing Research 51(4), 487-507.

Gabaix, X. (2014). A sparsity-based model of bounded rationality. Quarterly Journal of Economics 129(4), 1661-1710.

Goren, H., R. Kurzban, and A. Rapoport (2003). Social loafing vs. social enhancement: Public goods provisioning in real-time with irrevocable commitments. Organizational Behavior and Human Decision Processes 90(2), 277-290.

Henrich, J., S. Heine, and A. Norenzayan (2010). The weirdest people in the world? Behavioral and Brain Sciences 33(2-3), 61-83.

Isaac, R., D. Schmidtz, and J. Walker (1989). The assurance problem in a laboratory market. Public Choice 62(3), 217-236. 
Kurzban, R., K. McCabe, V. Smith, and B. Wilson (2001). Incremental commitment and reciprocity in a real-time public goods game. Personality and Social Psychology Bulletin 27(12), 1662-1673.

List, J. and D. Lucking-Reiley (2002). The effects of seed money and refunds on charitable giving: Experimental evidence from a university capital campaign. Journal of Political Economy 110(1), 215-233.

Marks, M. and R. Croson (1998). Alternative rebate rules in the provision of a threshold public good: An experimental investigation. Journal of Public Economics 67(2), 195-220.

Marx, L. and S. Matthews (2000). Dynamic voluntary contribution to a public project. Review of Economic Studies 67(2), 327-358.

Mehta, J., C. Starmer, and R. Sugden (1994). The nature of salience: An experimental investigation of pure coordination games. American Economic Review 84(3), 658-673.

Mollick, E. (2014). The dynamics of crowdfunding: An exploratory study. Journal of Business Venturing 29(1), 1-16.

Palfrey, T. and H. Rosenthal (1984). Participation and the provision of discrete public goods: A strategic analysis. Journal of Public Economics 24(2), 171-193.

Pitschner, S. and S. Pitschner-Finn (2014). Non-profit differentials in crowd-based financing: Evidence from 50,000 campaigns. Economics Letters 123(3), 391-394.

Rondeau, D. and J. List (2008). Matching and challenge gifts to charity: Evidence from laboratory and natural field experiments. Experimental Economics 11(3), 253-267.

Schelling, T. (1960). The Strategy of Conflict. Harvard University Press.

Solomon, J., W. Ma, and R. Wash (2015). Don't wait!: How timing affects coordination of crowdfunding donations. In Proceedings of the 18th ACM Conference on Computer Supported Cooperative Work \& Social Computing, pp. 547-556. ACM.

Spencer, M., S. Swallow, J. Shogren, and J. List (2009). Rebate rules in threshold public good provision. Journal of Public Economics 93(5), 798-806.

Stiver, A., L. Barroca, S. Minocha, M. Richards, and D. Roberts (2015). Civic crowdfunding research: Challenges, opportunities, and future agenda. New Media and Society 17(2), 249-271. 
Strausz, R. (2017). A theory of crowdfunding: A mechanism design approach with demand uncertainty and moral hazard. American Economic Review 107(6), 1430-1476.

van de Kragt, A., J. Orbell, and R. Dawes (1983). The minimal contributing set as a solution to public goods problems. American Political Science Review 77(1), 112-122.

Van de Rijt, A., S. Kang, M. Restivo, and A. Patil (2014). Field experiments of successbreeds-success dynamics. Proceedings of the National Academy of Sciences 111(19), 6934-6939.

Wash, R. and J. Solomon (2014). Coordinating donors on crowdfunding websites. In Proceedings of the 17th ACM Conference on Computer Supported Cooperative Work \& Social Computing, pp. 38-48. ACM. 


\section{Appendix A: User Interface}

Figure 7 displays a screenshot of the user interface at the start of the experiment for the benchmark treatment BEN, with information (in Dutch) as described in Section 2.3. Via a tab subjects can switch between this screen and the instructions (see Appendix E).

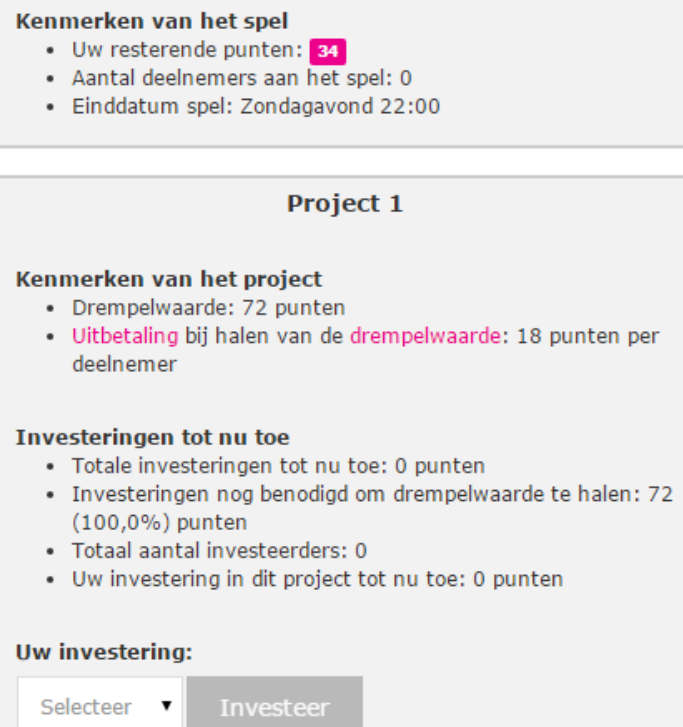

Project 2

Kenmerken van het project

- Drempelwaarde: 84 punten

- Uitbetaling bij halen van de drempelwaarde: 24 punten per

deelnemer

Investeringen tot nu toe

- Totale investeringen tot nu toe: 0 punten

- Investeringen nog benodigd om drempelwaarde te halen: 84 $(100,0 \%)$ punten

- Totaal aantal investeerders: 0

- Uw investering in dit project tot nu toe: 0 punten

Uw investering:

Selecteer $\mathbf{~ I n v e s t e e r ~}$

Figure 7: Screenshot of the user interface. 


\section{Appendix B: Seemingly irrational behavior}

We assess possible causes of three types of seemingly irrational behavior by linking our experimental outcomes to subjects' login and contribution behavior as well as the survey results, as described in Footnote 10 . We test for differences between two sub-samples: subjects who made one or more seemingly irrational decisions and subjects who did not. Results are reported in Table 6 .

Table 6: Mean values by seemingly irrational behavior

\begin{tabular}{lrrc}
\hline & $\begin{array}{c}\text { Rational } \\
\text { (mean) }\end{array}$ & $\begin{array}{c}\text { Irrational } \\
\text { (mean) }\end{array}$ & $\begin{array}{c}\text { Mann-Whitney } \\
\text { (p-value) }\end{array}$ \\
\hline Age & 49.12 & 54.50 & 0.00 \\
Education & 4.82 & 4.64 & 0.25 \\
Female & 1.52 & 1.44 & 0.19 \\
Household income & 14.25 & 14.73 & 0.58 \\
\hline \# Logins & 6.51 & 6.45 & 0.74 \\
\hline I give to society & 3.36 & 3.46 & 0.45 \\
I put family first & 3.61 & 3.57 & 0.56 \\
I find money decisions hard & 2.62 & 2.59 & 0.98 \\
\hline Goal: fair play & 3.52 & 3.55 & 0.85 \\
Goal: earn tokens & 4.12 & 3.93 & 0.04 \\
Goal: do as others & 2.26 & 2.34 & 0.70 \\
Goal: two projects & 3.98 & 3.92 & 0.51 \\
\hline Game: instructions not clear & 2.12 & 2.38 & 0.02 \\
Game: easy to play & 3.20 & 3.04 & 0.09 \\
Game: wanted to play more & 1.79 & 1.80 & 0.76 \\
\hline
\end{tabular}

Mean values of scores on selected survey items separated by whether or not subjects have displayed any of the three types of seemingly irrational behavior as described in the main text. All items are measured on a 5-point Likert scale, except 'Age' (yrs), 'Education' (8-point scale), 'Female (dummy=1)', 'Household income' (20-point scale), '\# Logins', 'Game: easy to play' (4-point Likert scale) and 'Game: wanted to play more' (yes/no). The third column displays the $p$ value of the associated Mann-Whitney rank-sum tests. 


\section{Appendix C: Supplementary regressions}

We check robustness of the results reported in Table 4 using two additional sets of regressions. In Tables 7 and 8 we provide an analysis of treatment effects on the difference and ratio of success between the target project and all other available projects. Recall that the target project for SEED72 and SIA, used in models (1) and (2) of both tables, is project $72_{18}$ (or $92_{18}$ when seeded) and the target project for SIXSEED78, used in Model (3) of both tables, is project $78_{17}$ (or $98_{17}$ when seeded). Contribution-difference in Table 7 is measured as contributions to the target project minus the sum of contributions to all other available projects, at the group level. Threshold-difference in Table 7 is measured as thresholds reached of the target project minus the sum of thresholds reached of all other available projects, at the group level. Given that each group can maximally reach two thresholds, the value of this dependent variable is $-2,-1,0$, or 1 . Contribution-ratio and threshold-ratio in Table 8 are measured in a similar way, but taking ratios rather than differences.

The results from both tables point in the same direction, confirming the results presented in the main text. Sign and significance of the coefficients for the treatment dummy in Models (2) and (3) indicate strong support for Hypothesis 3, while sign and significance of the coefficients for the treatment dummy in Model (1) indicates strong support for Hypothesis 4.

We check robustness of the results reported in Table 5 using two additional sets of regressions for the conservation experiment. In Tables 9 and 10 we provide an analysis of treatment effects on the difference and ratio of success between the target project and all other available projects. These tables and their interpretation are otherwise similar to Tables 7 and 8 . The results from both tables point in the same direction, confirming the results presented in the main text. 
Table 7: Treatment impacts on project success of the target project: differences. Compare Table 4

\begin{tabular}{|c|c|c|c|}
\hline & \multicolumn{2}{|c|}{ Project $72_{18}$} & \multirow{2}{*}{$\begin{array}{c}\text { Project } 78_{17} \\
(3) \\
\begin{array}{c}\text { Contribution- } \\
\text { difference }\end{array}\end{array}$} \\
\hline & $\begin{array}{l}(1) \\
\text { Contribution- } \\
\text { difference }\end{array}$ & $\begin{array}{l}\text { (2) } \\
\text { Threshold- } \\
\text { difference }\end{array}$ & \\
\hline SEED72 & $\begin{array}{r}5.649 \\
(13.90)\end{array}$ & $\begin{array}{c}1.031^{* *} \\
(0.458)\end{array}$ & \\
\hline SIA72 & $\begin{array}{c}-57.25^{* * *} \\
(13.92)\end{array}$ & $\begin{array}{c}-0.526 \\
(0.431)\end{array}$ & \\
\hline SIXSEED78 & & & $\begin{array}{c}43.54^{* *} \\
(20.63)\end{array}$ \\
\hline \# Subjects/group & $\begin{array}{c}-18.66 \\
(12.00)\end{array}$ & $\begin{array}{c}-0.816^{* *} \\
(0.390)\end{array}$ & $\begin{array}{r}-37.96^{*} \\
(20.52)\end{array}$ \\
\hline Constant & $\begin{array}{c}94.87 \\
(67.04)\end{array}$ & & $\begin{array}{r}65.78 \\
(115.6)\end{array}$ \\
\hline cut1 & & $\begin{array}{c}-6.370^{* * *} \\
(2.257)\end{array}$ & \\
\hline cut2 & & $\begin{array}{c}-4.967^{* *} \\
(2.192)\end{array}$ & \\
\hline cut3 & & $\begin{array}{c}-3.516 \\
(2.149)\end{array}$ & \\
\hline Observations & 40 & 40 & 27 \\
\hline
\end{tabular}

${ }^{*} p<0.10,{ }^{* *} p<0.05,{ }^{* * *} p<0.01$

Coefficient estimates from OLS regression models in (1) and (3) and ordered probit model in (2) (and standard errors in parentheses). All models are at the group level. The target project in (1) and (2) is project $72_{18}$ (or $92_{18}$ when seeded). The target project in (3) is project $78_{17}$ (or $98_{17}$ when seeded). Contributiondifference in (1) and (3) equals contributions to the target project minus the sum of contributions to all other available projects. Threshold-difference in (2) equals thresholds reached of the target project minus the sum of thresholds reached of all other available projects. Treatment names represent dummy variables, with BEN as the omitted reference treatment for (1) and (2) and SIX as the omitted reference treatment for (3). 
Table 8: Treatment impacts on project success of the target project: ratios. Compare Table 4

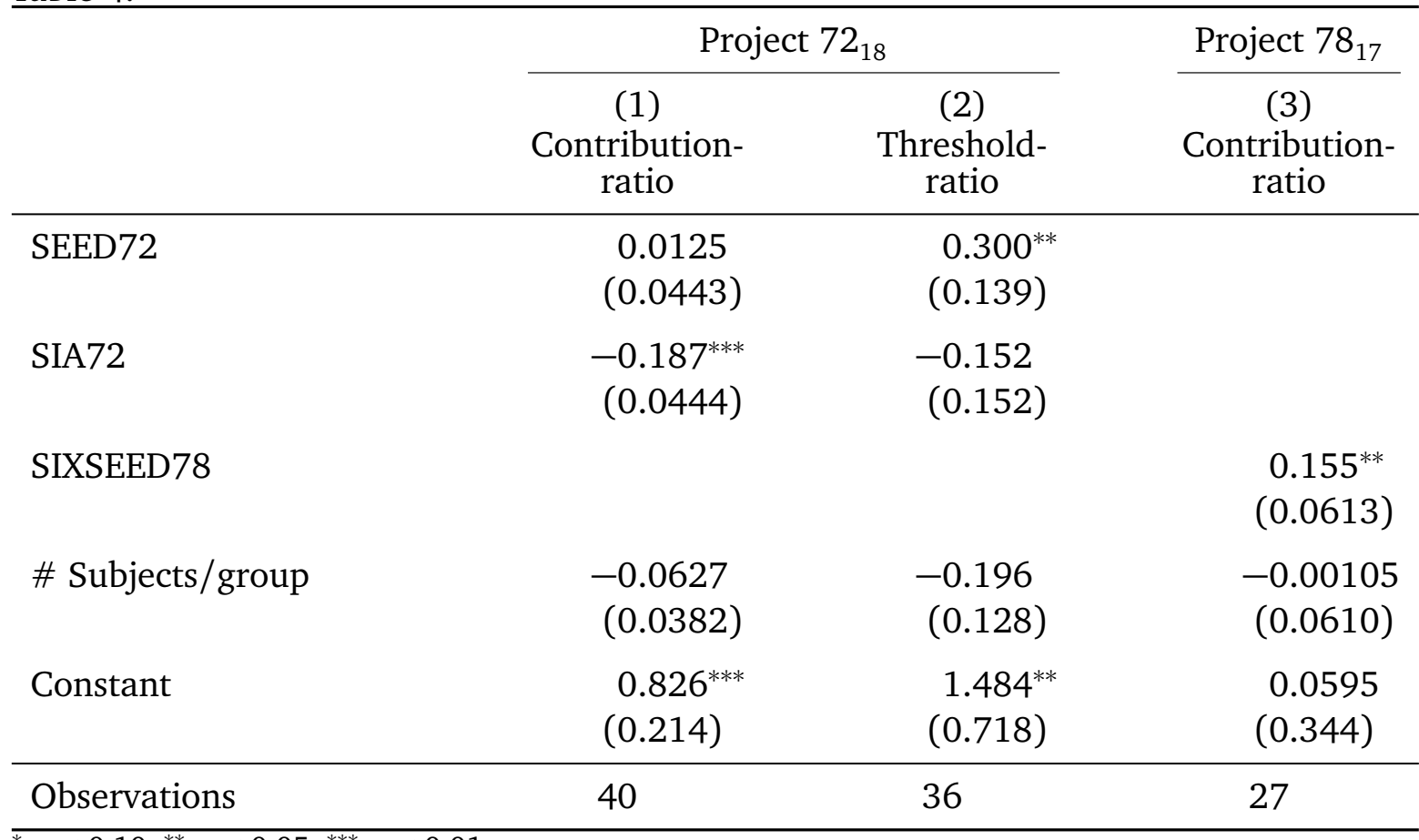

${ }^{*} p<0.10,{ }^{* *} p<0.05,{ }^{* * *} p<0.01$

Coefficient estimates from OLS regression models (and standard errors in parentheses). All models are at the group level. The target project in (1) and (2) is project $72_{18}$ (or $92_{18}$ when seeded). The target project in (3) is project $78_{17}$ (or $98_{17}$ when seeded). Contribution-ratio in (1) and (3) equals the ratio of contributions to the target project over the sum of contributions to all available projects per treatment. Threshold-ratio in (2) equals the ratio of thresholds reached of the target project over the sum of thresholds reached of all available projects per treatment. Treatment names represent dummy variables, with BEN as the omitted reference treatment for (1) and (2) and SIX as the omitted reference treatment for (3). 
Table 9: Results of the conservation experiment: Treatment impacts on project success of the target project: differences. Compare Table 5 .

\begin{tabular}{lcc}
\hline & \multicolumn{2}{c}{ Project $72_{18}$} \\
\cline { 2 - 3 } & $\begin{array}{c}(1) \\
\text { Contribution- } \\
\text { difference }\end{array}$ & $\begin{array}{c}\text { Threshold- } \\
\text { difference }\end{array}$ \\
\hline SEED72 & 7.636 & 0.0262 \\
SIA72 & $(13.25)$ & $(0.527)$ \\
& $-45.65^{* * *}$ & -0.611 \\
\# Subjects/group & $(12.80)$ & $(0.509)$ \\
Constant & -8.084 & -0.424 \\
& $(11.40)$ & $(0.439)$ \\
cut1 & 29.71 & -3.169 \\
cut2 & $(60.81)$ & $(2.361)$ \\
& & -0.851 \\
\hline Observations & & $(2.353)$ \\
\hline${ }^{*} p<0.10,{ }^{* *} p<0.05,{ }^{* * *} p<0.01$ & 35 & 35 \\
\hline
\end{tabular}

Coefficient estimates from OLS regression model in (1) and ordered probit model in (2) (and standard errors in parentheses). All models are at the group level. The target project in (1) and (2) is project $72_{18}$ (or $92_{18}$ when seeded). Contribution-difference in (1) equals contributions to the target project minus the sum of contributions to all other available projects. Threshold-difference in (2) equals thresholds reached of the target project minus the sum of thresholds reached of all other available projects. Treatment names represent dummy variables, with BEN as the omitted reference treatment. 
Table 10: Results of the conservation experiment: Treatment impacts on project success of the target project: ratios. Compare Table 5 .

\begin{tabular}{lcc}
\hline & \multicolumn{2}{c}{ Project $72_{18}$} \\
\cline { 2 - 3 } & $\begin{array}{c}(1) \\
\text { Contribution- } \\
\text { ratio }\end{array}$ & $\begin{array}{c}(2) \\
\text { Threshold- } \\
\text { ratio }\end{array}$ \\
\hline SEED72 & 0.0351 & -0.0980 \\
SIA72 & $(0.0625)$ & $(0.302)$ \\
& $-0.164^{* *}$ & -0.255 \\
\# Subjects/group & $(0.0604)$ & $(0.231)$ \\
Constant & -0.0186 & 0.0784 \\
& $(0.0538)$ & $(0.231)$ \\
\hline Observations & $0.548^{*}$ & -0.0392 \\
\hline$p<0.10, * 204)$
\end{tabular}

${ }^{*} p<0.10,{ }^{* *} p<0.05,{ }^{* * *} p<0.01$

Coefficient estimates from OLS regression models (and standard errors in parentheses). All models are at the group level. The target project in (1) and (2) is project $72_{18}$ (or $92_{18}$ when seeded). Contribution-ratio in (1) equals the ratio of contributions to the target project over the sum of contributions to all available projects per treatment. Threshold-ratio in (2) equals the ratio of thresholds reached of the target project over the sum of thresholds reached of all available projects per treatment. Treatment names represent dummy variables, with BEN as the omitted reference treatment. 


\section{Appendix D: Conservation experiment figures}

The below figures repeat Figures 1 3 using data from the conservation experiment.

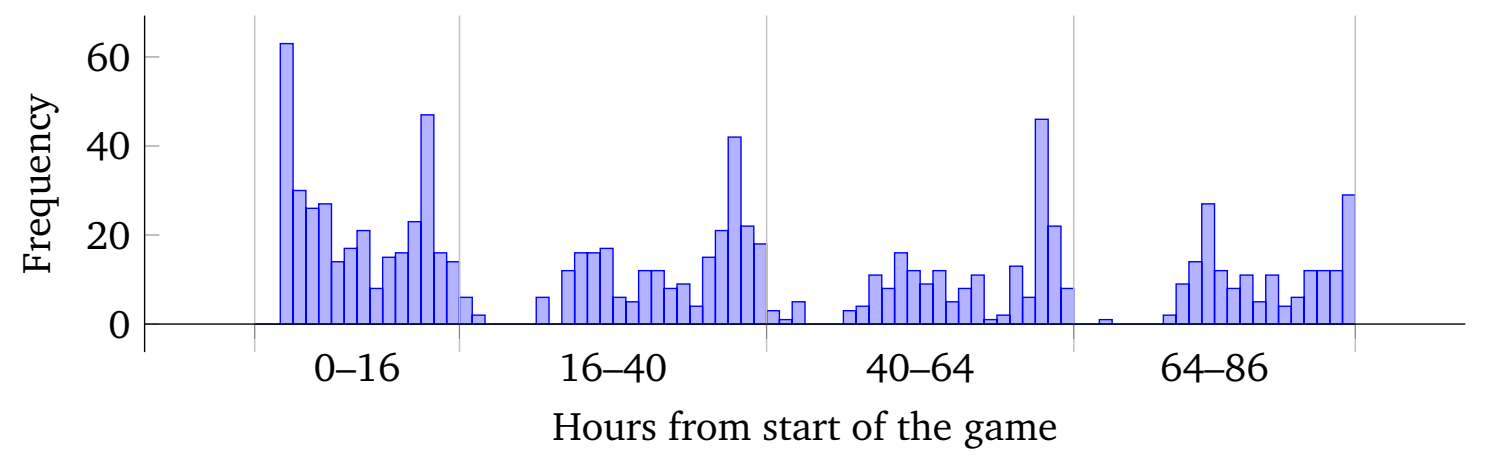

Figure 8: Conservation experiment: Investment frequency across all treatments in one-hour bins. Hour 0 corresponds to THU 08:00 and hour 86 corresponds to SUN 22:00. Compare Figure 1 .

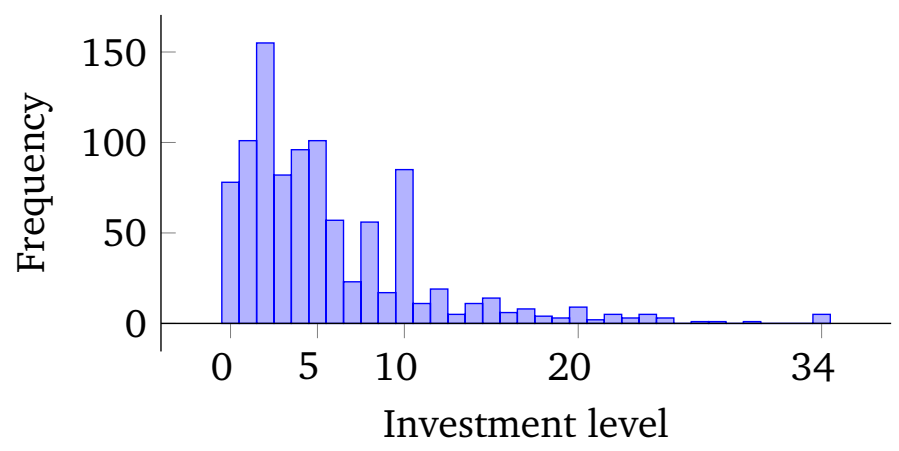

Figure 9: Conservation experiment: (Non-aggregated) investment level frequency across all treatments. Compare Figure 2 .

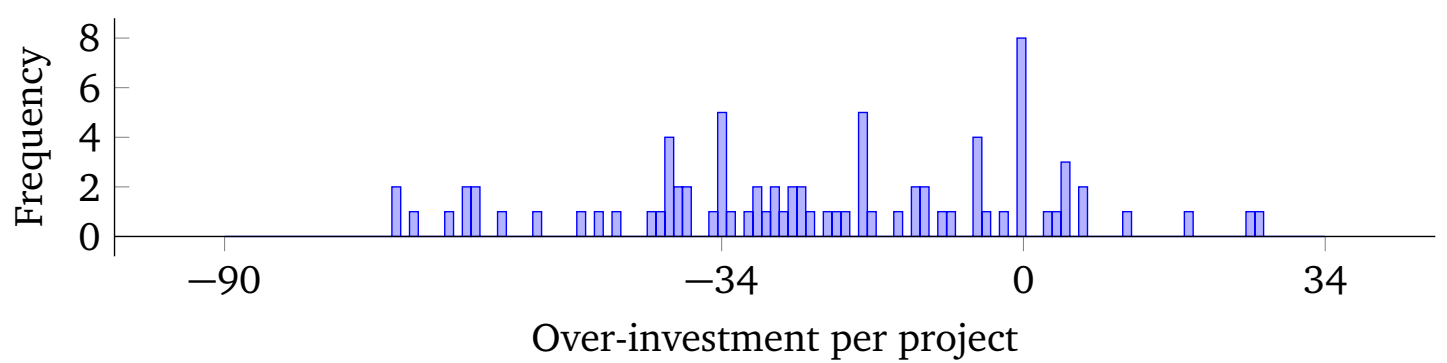

Figure 10: Conservation experiment: Project over-investment frequency in tokens across all treatments. Compare Figure 3 . 


\title{
Appendix E: Instructions
}

\author{
(Translated from Dutch)
}

\section{Introduction}

Welcome and thank you for joining. Your participation is completely anonymous. Any results will solely be used for research purposes and will not be shared with others.

You will participate in a game. In the game you will be shown a number of projects in which you and the other participants in the game can invest. You and the other participants receive a number of tokens to invest in these projects. By investing, the group of participants, or part of the group, can make sure that a project is successful. Successful projects generate a payoff to all members of the group, including those that did not invest. Bottom-line is that it is your decision what to do with the tokens that you receive. It is not possible to make mistakes.

At the end of the game, on Sunday-night 22:00, the tokens that you earned in the game will be converted to money and this money will be credited to your bank-account by TNS-NIPO. The number of tokens that you earn depend on the decisions that you and the other participants make in the game. Hence, you are making real investment decisions. After the game ends, you will be sent a survey to fill out.

The game is further introduced below. It is important to read this information carefully. Next you can start the game via the "Game" button in the top right corner of your screen.

\section{Projects in the game}

All participants have the option to invest in the projects up to the end of the game. There will be no additional projects and no projects will be canceled. The description of each project is based on two characteristics: threshold and payoff. The thresholds and payoffs are different for each project and they remain unchanged throughout the game. Both characteristics are further explained below.

Threshold: The threshold is the number of tokens required to make the project succeed. The threshold can be reached by investments from you and the other participants in the game. Two important rules are the following:

1. When the total level of investments is equal to or higher than the threshold, the project is successful. The invested tokens will be used to carry out the project.

2. When the total level of investments is equal to or higher than the threshold, the project is not successful. Any investments made will be returned to the players.

Payoff: The payoff is the number of tokens that is given to each participant if the project is successful. If a project is successful, EVERYONE receives the payoff, including those that did NOT invest in this project. We do this since many projects, including projects financed by crowdfunding, involve benefits to people that did not invest in the project themselves.

\section{The main rules of the game}


1. You are member of a group of 6 participants. Each one of you receives, once-only, 34 tokens at the start of the game. This implies that the group as a whole owns 204 tokens at the start of the game.

2. The value of each token is 20 Euro-cents. Your 34 tokens at the start of the game are worth 6.80 Euro. By investing tokens in projects you can earn more tokens.

3. You may invest but you are not required to do so. During the game, no projects will be added or dropped. Also, the characteristics of the project remain unchanged throughout the game.

4. You may invest at any moment during the course of the game.

5. You may invest multiple times in the same project.

6. You may invest in more than one project. The group as a whole owns a sufficient number of tokens to successfully fund two projects.

7. Once you have made an investment, this action cannot be canceled. When the project is not successful, your investment will be returned to you. When the project is successful, each player receives the corresponding payoff.

8. The game ends on Sunday night 22:00. At that time the successful projects will be identified, your final number of tokens will be calculated, and converted into money units (20 Euro cents per token).

9. Your final number of tokens equals the sum of: (start tokens) - (invested tokens) + (returned tokens for unsuccessful projects) + (payoff tokens for successful projects).

\section{Example}

The characteristics of project $A$ are: threshold 60 and payoff 15 . You do not invest in project $A$. Because other participants do invest in project $A$, the threshold is reached and the project is successful. Each participant receives a payoff of 15 tokens.

The characteristics of project $B$ are: threshold 82 and payoff 20. During the game you invest a total of 10 tokens ( 6 tokens on Saturday and 4 tokens on Sunday) in project B. Other participants also invested in project $B$, but the threshold is not reached and the project is not successful. Your invested 10 tokens are returned to you.

Your final number of tokens at the end of the game is calculated as follows:

Start tokens

- invested tokens: 10 tokens in project B

+ returned tokens for unsuccessful projects: 10 tokens for project $B$

+ payoff tokens for successful projects: 15 tokens for project $A$

$=$ final number of tokens at the end of the game
34

$-10$

$+10$

$+15$

$=49$

In this example you would have earned 15 more tokens compared to the number of start tokens (the 34 tokens at the start of the game), and your bank account would have been credited by 9.80 Euro $(=49 * 20$ Euro cents).

\section{Requirements}

There are three requirements that you should meet:

1. For four days, you should log in at least once each day on the game website. 
2. You should decide at least once per day whether you want to make an investment, and if so, in which project or projects, and make this decision on the game website.

3. After the game ends you will be sent a survey that you should fill out completely.

\section{What to do when you log in?}

Each time that you log in we ask you to take the following actions:

1. Have a close look at the projects. The thresholds and payoffs remain unchanged throughout the game. The total investments and the number of investors may of course change, depending on your investments and those of the other participants. This information is updated continuously.

2. Determine whether you want to make an (additional) investment during this login, and if so, how many tokens. Take into account that the sum of your investments cannot exceed 34 tokens.

3. Make your decision by choosing your investment from the drop-down list of the relevant project.

\section{Frequently asked questions}

1. Can I lose money in this game? ANSWER: No, this is not possible. It is possible to lose part of your 34 tokens that you receive at the start of the game. This is possible only when you invest more tokens in a project than the level of the payoff and the project happens to be successful (if it were not successful your invested tokens would be returned to you).

2. What happens when investments exceed the threshold? ANSWER: Nothing. Suppose a project has a threshold of 100 tokens and the total investments in this project equal 105 tokens. Every participant receives this project's payoff but the 5 tokens 'over-investment' are not returned.

3. What is the best moment to invest and in which project? ANSWER: This depends on your personal preferences. You can use all information provided on the game website to decide when and in which project to invest. This information includes the threshold and payoff, but also past investments by you and the other participants in the game.

4. Can I invest more than $\mathbf{3 4}$ tokens? ANSWER: No, you cannot invest more than the 34 tokens you receive at the start of the game. It is also not possible to purchase more tokens.

5. Can I see which other players have already invested? ANSWER: The game website shows per project the total level of investments made as well as the number of players that has already invested. The website does not show the identity of these players, when they invested, or how many was invested by each player.

For other questions, please contact $<$ Contact Information $>$. 